\title{
CONTIGUITY IN PROSODIC WORDS: EVIDENCE FROM SPANISH
}

\author{
KAROLINA BROŚ \\ University if Warsaw \\ k.bros@uw.edu.pl
}

\begin{abstract}
Spanish dialects show substantial variation in coda $s$ weakening. Yet, to provide a comprehensive treatment of this phenomenon, a bigger prosodic constituent than just the coda position should be analysed. Crucially, two aspirating varieties of Spanish are considered. The Granada dialect weakens $s$ to [h] inside words, at word edges and at prefix edges. The process may be either transparent (esto [éh.to] 'this', des-calzar [deh.kal.sár] 'to unshoe', las cosas [lah.kó.sah] 'the things') or opaque (des-hecho [de.hé.tfo] 'undone', las aguas [la.há.ywah] 'the waters'). Chilean Spanish, on the other hand, presents transparent (esto [éh.to] 'this', des-calzar [deh.kal.sár] 'to unshoe') and opaque (las aguas [la.há. ywa] 'the waters') aspiration, as well as deletion (las cosas [la.kó.sa] 'the things'), and no aspiration across a prefix boundary (des-hecho [de.sé.t fo] 'undone'). The reported variable behaviour calls for an integrated approach to segmental weakening across all prosodic constituents, and for a revision of the present understanding of contiguity. The boundary between the prefix and the stem is protected by the grammar despite the weak coda position of the prefix-final $s$, therefore the domain of application of the CONTIGUITY constraint should be extended to the supramorphemic level.
\end{abstract}

KEYWORDS: Contiguity; $s$ weakening; Spanish aspiration; Chilean; Spanish prefixes.

\section{Introduction $^{1}$}

Spanish dialects present substantial variation in the treatment of coda $s$, most of them showing some degree of segment weakening: e.g. debuccalisation to [h]

\footnotetext{
${ }^{1}$ I would like to thank PSiCL's anonymous reviewers for discussion and criticism, which led to considerable improvement of this paper, both in terms of content and presentation. However, let me add that the responsibility for this article is solely mine.
} 
inside words and at word edges (also known as aspiration), analysed as lenition. In diachronic terms, this gives rise to systemic changes whereby an otherwise non-existent sound $[\mathrm{h}]$ is added to the inventory and another sound, [s], slowly vanishes. In synchronic terms, inter- and intradialectal variability can be observed with different contexts and domains of application of the process. The vast majority of generative analyses suggest that this general process of $s$ weakening encompasses a series of strategies employed to deal with a marked structure: $s$ standing in a coda, i.e. a prosodically weak position. ${ }^{2}$ Thus, lenition extends from preconsonantal contexts inside words and at word boundaries to prepausal environments and prevocalic position in some Spanish varieties, where it is additionally obscured by resyllabification (see Lipski 1996 for a descriptive overview). ${ }^{3}$ This is observed in the Spanish of Granada, which is one of the dialects studied in this paper. The relevant forms are: esto [éh.to] 'this', des-calzar [deh.kal.sár] 'to unshoe', des-hecho [de.hé.t5o] 'undone', las cosas [lah.kó.sah] 'the things', las aguas [la.há.ywah] 'the waters'. Interestingly, in the most radical dialects, another weakening process can be observed: in Chilean, coda $s$ is dispreferred altogether and deleted (las cosas [la.kó.sa] 'the things', vez [be] 'time') unless it would disrupt morpheme contiguity, i.e. involve the elimination of a segment from the middle of a contiguous string (esto [éh.to] 'this'). Against this background, prefix-final $s$ resists deletion although such a process would have no effect on the integrity of the stem - in prefixed words the $s$ stands at the edge of the affix and not inside any morpheme (descalzar [deh.kal.sár] 'to unshoe'). What is more, no aspiration occurs across a prefix boundary before a vowel in this dialect (des-hecho [de.sé.tfo] 'undone').

The aim of this paper is to look for an integrated theory of $s$ weakening based on evidence from the two Spanish dialects mentioned above and to confront the presented data with the Stratal OT mechanism (Bermúdez-Otero 2003, 2006; Kiparsky 1999, 2003; Rubach 1997, 2000). Furthermore, the paper discusses the notion of contiguity and proposes that it should be extended to the supramorphemic level. Given the behaviour of prefixed words, I argue that although the affix is traditionally considered a weak position (Casali 1996), radical changes in the form of deletion are prohibited in the domain of a whole prosodic word containing the affix in the same way they are banned morphemeinternally. Consequently, the boundary between the prefix and the stem is pro-

\footnotetext{
${ }^{2}$ I discuss the treatment of $s$ aspiration as positional weakening in Section 2.

${ }^{3}$ Note that onset $s$ seems immune to such weakening. Onset $s$ lenition is present only in a few Latin American dialects in a strictly limited set of words, which is probably induced by word frequency effects (e.g. Lipski 1996).
} 
tected by the grammar, which can be formalized with the use of a supramorphemic contiguity constraint.

As will be demonstrated in the following sections, a stratal approach is necessary to account for opaque interactions encountered in Spanish although the portion of the analysis related to the prefix alone might be presented successfully without recourse to level distinction, at least for some dialects. Given the whole of the Spanish consonantal phonology, however, I shall retain this integrated stratal approach and present it here. Also, it is worth mentioning that at least one successful attempt at dealing with Spanish $s$ aspiration in the framework of Stratal OT has been made so far. Kaisse and McMahon (2011) present a convincing analysis of Río Negro Argentinian - a partial analogue of Chilean Spanish discussed here. The difference lies in the presence of deletion as an alternative strategy. A stratal approach to Río Negro Argentinian has also been presented by Roca (2005) who points to the problems generated by outputoutput approaches (to be discussed in Section 4) and presents a two-level evaluation, although he does not discuss dialectal variation. The contribution made here is twofold: first, deletion is a complication that requires a revised approach in Stratal OT; second, the extended contiguity constraint requires level distinctions for prosodification purposes.

The paper is structured as follows. Section 2 presents the data and the theoretical assumptions. Section 3 provides an analysis of the data under the Stratal OT framework and then discusses the treatment of prefixes alongside the rest of $s$ weakening facts. Other accounts of $s$ aspiration in Spanish with an emphasis on the treatment of prefixes are summarised and discussed in Section 4. Finally, Section 5 concludes the discussion.

\section{Data and theoretical assumptions}

According to the abundant literature concerning Latin-American dialects, the process of $s$ weakening has a wide array of manifestations across Spanish language varieties and involves various types of interaction with other phonological processes encountered in the Spanish language in general. Furthermore, it can be subdivided into several advancement stages. As Lipski (1999: 198) puts it:

$s$ weakens to [h] in preconsonantal contexts (via autosegmental bleaching of supralaryngeal features) [...]; (at) the second stage, syllable-final $s$-reduction extends to all syllable-final contexts, including 
phrase-final [...] while retaining word-final prevocalic s. [...] the extension to include word-final prevocalic $s$ occurs in the phonologically most advanced dialects. ${ }^{4}$

In the most common scenario, coda $s$ is weakened to [h] both word-medially and word-finally, which can be analysed as a coda condition against $s$.

In this paper, I present data from two aspirating dialects of Spanish: Granada and Chile. The Granada dialect is analysed e.g. by Colina (1997) and Kenstowicz (1996), whose contributions are discussed in Section 4. I base the Granada data on the observations and examples provided by these authors. Note, however, that there exist other styles within the Granada variety in which the deletion of final $[\mathrm{h}]$ corresponding to underlying $s$ is permitted (e.g. Tejada 2012). Such cases are very similar to Chilean Spanish presented below. Most importantly, however, the crucial interdialectal difference pointed out here as evidence for contiguity in prosodic words, i.e. the different behaviour of prefixfinal $s$, holds in all subdialectal variations of Granada Spanish. These facts apart, it must be pointed out that this paper examines one particular variant of the Granada dialect in which no deletion occurs.

The Chilean data are based on my fieldwork in northern Chile and on personal communication with Hernán Emilio Pérez Muñoz, a phonetician from the University of Concepción, Chile, as well as native consultants: Rodrigo Andrés Vivanco Torres and Jorge Esparza Inostroza. The data were gathered in the form of digital recordings in 2011 and then transcribed. All speakers were middleclass natives from the north of Chile aged between 25 and 40. The fieldwork and data were discussed in Broś $(2013,2015)$. Most importantly, it must be noted that spontaneous, rapid speech was the focus of the study. In this case, aspiration and deletion are categorical and show no signs of phonetic gradiency. Occasional undeleted [h] derived from $s$ appears only in the case of careful speech, elicited repetitions, pauses and hesitations. All in all, there is no variation within

\footnotetext{
${ }^{4} \mathrm{He}$ further claims that " $[\mathrm{p}] \mathrm{revocalic} s$-reduction has no direct phonetic motivation as weakening in the syllabic rhyme, but is rather an analogical extension which results in paradigmatic regularity", which suggests non-phonetic grounding of aspiration in the most advanced cases, in line with the lexical diffusionist doctrine. Paradigmatic and frequency effects have been discussed e.g. by Bybee $(2000,2003)$ who argues that aspiration in Spanish is extended to intervocalic context across a word boundary by analogy. Although her analysis is successful in the case of pronouns and articles, it is unable to explain similar changes in other grammatical categories and therefore must be rejected. A full demonstration of its incompatibility with the data has to be spared here for reasons of space, but compare the Chilean data presented below and see Hualde (2011) for a discussion of frequency effects in Spanish language change.
} 
a single speaker in rapid speech. Therefore, I assume categorical phonological changes in my analysis of Chilean. The data presented here are partially confirmed by previous descriptive works (e.g. Henríquez Ureña 1921; Oroz 1966; Cepeda 1990; Lipski 1996) and more recent sociolinguistic studies (e.g. Pérez 2007; Borland 2004). To facilitate the comparison between the two dialects taken under scrutiny here, examples (1-4) present actual productions from my Chilean recordings, as well as the expected productions of the same words and sequences to be found in the Granada variety, based on the generalizations and descriptions provided in the literature. The third option visible in the tables comes from non-aspirating dialects such as Northern Peninsular Spanish. I present these productions in order to show the crucial dialectal differences between aspirating and non-aspirating Spanish varieties. ${ }^{5}$

(1) Word-internal and word-final $s$ in individual words

(1a) Preconsonantal

$\begin{array}{lll}\text { Chilean } & \text { Granada-type aspirating } & \text { Peninsular non-aspirating } \\ \text { esto 'this' [éh.to] } & \text { esto 'this' [éh.to] } & \text { esto 'this' [és.to] } \\ \text { desde 'from' [déh.ðe] } & \begin{array}{l}\text { desde 'from' [déh.ðe] } \\ \text { justo 'just' [xuh.to] }\end{array} & \text { insto 'just' [xuh.to] 'from' [déz.ðe] } \\ \text { iusto 'just' [xus.to] }\end{array}$

(1b) Prevocalic

Chilean

sano 'healthy' [sá.no] cosa 'thing' [kó.sa] tenso 'tense' [tén.so]
Granada-type aspirating sano 'healthy' [sá.no] cosa 'thing' [kó.sa] tenso 'tense' [tén.so]
Peninsular non-aspirating

sano 'healthy' [sá.no] cosa 'thing' [kó.sa] tenso 'tense' [tén.so]

\footnotetext{
${ }^{5}$ Note that the threefold division is aimed solely at pointing out the most important interdialectal differences, especially opacity effects and the behaviour of prefixes. By no means is it an exhaustive presentation of the complexity $s$ lenition presents. A comprehensive typology of aspirating Spanish dialects was presented by Kaisse (1999) and then used as a point of departure for phonological analysis by e.g. Wiltshire (2002, 2006), or Harris and Kaisse (1999). This typology, however, includes $s$ aspiration only. Deletion is not taken into account in the dialectal classification nor in the analyses, which is of consequence for the proposed solutions.
} 
(1c) Prepausal

\begin{tabular}{|c|c|c|c|c|c|}
\hline Chilean & & Granada-type a & pirating & Peninsular non- & aspirating \\
\hline vez 'time' & [bé] & vez 'time' & [béh] & vez 'time' & {$[\text { bé } \theta]^{6}$} \\
\hline veces 'times' & [bé.se] & veces 'times' & [bé.seh] & veces 'times' & 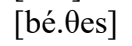 \\
\hline muchos 'many' & [mú.tfo] & muchos 'many' & [mú.tfoh] & muchos 'many' & [mú.tfos] \\
\hline
\end{tabular}

In (1) above, $s$-aspiration can be observed inside words only in Chilean and both inside words and word-finally in Granada-type dialects. Deletion prevails wordfinally in the first case. The situation is further complicated in phrase phonology.

(2) Word-final $s$ across a word boundary

(2a) Preconsonantal

\begin{tabular}{|c|c|c|}
\hline hilean & Granada-type aspirating & non-asp \\
\hline$o s$ 'o & ot & otros puertos 'other ports' \\
\hline & & \\
\hline Is normativas 'the rules' & las norm & las nor \\
\hline & & \\
\hline $\begin{array}{l}\text { a vez } \\
{[\mathrm{u} .1}\end{array}$ & $\begin{array}{r}\text { una ver } \\
{[\mathrm{u} .}\end{array}$ & $\begin{array}{r}\text { una vez } \\
\text { [u. }\end{array}$ \\
\hline
\end{tabular}

(2b) Prevocalic

$\begin{array}{ccc}\text { Chilean } & \text { Granada-type aspirating } & \text { Peninsular non-aspirating } \\ \text { unas enfermedades } & \text { unas enfermedades } & \text { unas enfermedades } \\ \text { 'some diseases' } & \text { 'some diseases' } & \text { 'some diseases' } \\ \text { [u.na.hen.fer.me.ðá.ðe] } & \text { [u.na.hen.fer.me.ðá.ðeh] } & \text { [u.na.sen.fer.me.ðá.ðes] } \\ \text { escuchamos una crítica } & \text { escuchamos una critica } & \text { escuchamos una crítica } \\ \text { 'we were criticised' } & \text { 'we were criticised' } & \text { 'we were criticised' } \\ \text { [eh.ku.tfá.mo.hu.na...] } & \text { [eh.ku.tfá.mo.hu.na...] } & \text { [es.ku.tfá.mo.su.na...] } \\ \text { una vez entré } & \text { una vez entré } & \text { una vez entré } \\ \text { 'once I entered' } & \text { 'once I entered' } & \text { 'once I entered' } \\ \text { [u.na.ßé.hen.tı́.] } & \text { [u.na.ßé.hen.tré] } & \text { [u.na.ßé.Oen.tré] }\end{array}$

\footnotetext{
${ }^{6}$ The Northern Peninsular varieties of Spanish distinguish between $/ \mathrm{s} /$ and $/ \theta /$. The dental fricative is represented with the graphemes $<\mathrm{z}>$ and $<\mathrm{c}>$ when followed by front vowels. In Latin American Spanish, in the Canary Islands and most parts of Andalusia, including Granada, the two sounds merged and $[\mathrm{s}]$ is produced instead of [ $\theta]$. The phenomenon is known as seseo.
} 
As demonstrated in (2), Chilean presents an interesting interaction of coda $s$ aspiration and deletion. ${ }^{7}$ Across a word boundary, either deletion or debuccalisation applies, depending on what follows. Before a consonant, $s$ is lost similarly to the $s$ in isolated words before a pause (2a, cf. example 1). Before a vowel, however, an opacity effect may be observed ( $2 b)$. Note that Spanish exhibits resyllabification across word boundaries whereby all empty onsets are filled by word-final consonants. ${ }^{8}$ In the case of Chilean, the coda segment is forced into the empty onset position of the following word, but its featural specification changes (e.g. in unas enfermedades 'some diseases' [u.na.hen.fer.me.ðá.ðe]). It is thus [h] that surfaces as the onset of the following word - a visible trace of $s$ aspiration with no manifest motivation in a surface-based approach. A similar opacity effect can be observed in the Granada dialect, although without the

\footnotetext{
${ }^{7}$ As noted by a reviewer, the presence of the fricative in word-final position carries a high functional load, deletion is therefore counterintuitive as it may lead to contrast neutralisation. Note, however, that final $s$ in Spanish is also highly predictable from the context, e.g. as a plural marker or part of the 1st person plural -mos inflectional morpheme in verbs. Given the use of demonstrative and personal pronouns, as well as articles in clitic position and adjectives as attributes of nouns, the underlying contrast may not be as important for speech comprehension after all. I have not noticed any compensatory phonetic changes resulting from $s$ deletion nor have there been any studies on Chilean pointing to them to the best of my knowledge. A separate phonetic study focused on these issues is required to establish whether there exist certain subtle subphonemic cues signalling contrast and near-merger rather than full neutralisation. For now, this is outside the scope of this paper and in the absence of such evidence I assume that $s$ deletion in Chilean is categorical. It is worth mentioning, however, that in deleting Granada varieties, the loss of $s$ usually implies the opening of the previous vowel, which ensures that the underlying morphological information is not lost (Lloret and Jiménez 2009).

${ }^{8}$ I take the traditional approach to Spanish syllabification, following Harris (1983) and others, and based on a series of empirical observations made during my fieldwork. First, Chilean speakers typically present no phonetic features that might suggest the lack of resyllabification: syllable to syllable transitions across words are very smooth (minimal pairs of the type papel es 'paper is' and papeles 'papers' look indistinguishable), there are no glottal stop insertions or any other sounds or boundaries intervening except for intonational pauses. The latter phenomenon seems to confirm Mathews' (1994) claim that resyllabification applies only up to the end of an intonational phrase. Other facts suggesting that resyllabification should be embraced in analysing Chilean include lack of $/ \mathrm{r} /$ devoicing in derived onsets as opposed to final codas (also see Lipski 1996), consonant deletion blocking across a word boundary in words such as ciudad 'town' or cantidad 'number' [kan. ti.ðá] vs. cantidad importante 'significant number' [kan.ti.ðá.ðim.por.tán.te] / [kan.ti.ðá.Oim.por. tán.te], as well as vowel merger, deletion and gliding. Note, however, that there has been some debate concerning the parsing of word-final consonants in Spanish as onsets in connected speech (Lipski 1999; Bradley 2005; Robinson 2012; Hualde and Prieto 2014; Strycharczuk and Kohlberger 2016). A separate study on Chilean is necessary, however, to see whether the objections presented by these authors are confirmed.
} 
complication in the form of elision before a consonant or a pause ([u.na.hen.fer. me.ðá.ðeh]. ${ }^{9}$

If we were to analyse these non-transparent cases by means of a derivational account, we would require a proper rule ordering where aspiration applies first, followed by resyllabification and then deletion (in the Chilean variety). Under such an analysis, [h] would surface word-medially as in (1a) and across a word boundary before a vowel as in (2b), while total segmental loss would be observed in Chilean word-finally before a consonant or a pause, as in (2a) and in (1c), respectively. Needless to say, aspirating dialects presenting no elision (Granada) would have no deletion rule and thus [h] would be the end result across all cases. This is illustrated in (3) below.

(3) Rule-based derivation of veces 'times', una vez entré 'once I entered' and una vez comi 'once I ate 10

$\begin{array}{clll}\text { 'times' } & \text { 'once I entered' } & \text { 'once I ate' } & \text { Processes } \\ \text { be.ses } & \text { una + bes + entre } & \text { una + bes + komi } & \text { Underlying form } \\ \text { be.ses } & \text { u.na.bes.en.tre } & \text { u.na.bes.ko.mi } & \text { Syllabification } \\ \text { bé.ses } & \text { u.na.bés.en.tré } & \text { u.na.bés.ko.mí } & \text { Stress Assignment } \\ \text { bé.seh } & \text { u.na.béh.en.tré } & \text { u.na.béh.ko.mí } & \text { Aspiration } \\ \text { bé.seh } & \text { u.na.bé.hen.tré } & \text { u.na.béh.ko.mí } & \text { Resyllabification } \\ \text { bé.se } & \text { u.na.bé.hen.tré } & \text { u.na.bé.ko.mí } & \text { Deletion (in Chilean) } \\ \text { bé.se } & \text { u.na.ßé.hen.tré } & \text { u.na.ßé.ko.mí } & \text { Spirantisation }{ }^{11}\end{array}$

Note that resyllabification must apply after aspiration and no other rule ordering would produce licit forms. ${ }^{12}$ What is more, it is vacuous whenever the onset po-

\footnotetext{
${ }^{9}$ There is a split between aspirating dialects that show opacity (overapplication) and those that do not (in which word-final $s$ is rendered $s$ before a vowel, with resyllabification blocking aspiration).

${ }^{10}$ The presented analysis is in line with derivational accounts presented in generative literature concerning Spanish segmental processes and resyllabification (Harris 1969; Hualde 1991).

${ }^{11}$ At the end of the derivation, I add spirantisation, which is responsible for turning voiced stops into approximants in connected speech, both inside words and across word boundaries. Its exact ordering, however, is irrelevant for the analysis presented here.
} 
sition is already filled. In a parallel account, such a solution is not at hand. The intermediate stage of $s$-aspiration across a word boundary before a vowel is not visible on the surface, hence the resultant change from $s$ to [h] is opaque. If Spanish debuccalisation is triggered by a coda condition against $s$, as is commonly believed (Morris 2000; Face 2002; Shepherd 2003; Harris 1983, 1993), there is no motivation for it in (3).

As the data presented above demonstrate, as opposed to other aspirating dialects, Chilean presents two distinct repair strategies to satisfy the coda condition against $s$ : aspiration and deletion, whose interaction leads to opacity by overapplication. ${ }^{13}$ As a result, aspiration manifests itself only in word-medial position and in opaque cases across a word-boundary. $S$ is lost completely at word edges before a pause or a consonant. What remains to be determined is the behaviour of prefixes across dialects. The table in (4) presents the relevant data.

(4) The behaviour of $s$ in prefixed words

\begin{tabular}{|c|c|c|}
\hline \multicolumn{3}{|r|}{ ng } \\
\hline des-calzar 'to unshoe' & des-calzar 'to unshoe' & des-calzar 'to unshoe' \\
\hline des-confiar 'to mistrust' & des-confiar & ' 'to mistrust' \\
\hline m fiácl & s & fís \\
\hline lone & des-hecho & des-hecho \\
\hline & & \\
\hline $\begin{array}{l}\text {-ilusión "disapp } \\
\text { [de.si.lu.sión] }\end{array}$ & $\begin{array}{l}\text {-ilusión “disapp } \\
\text { [de.hi.lu.sjón] }\end{array}$ & $\begin{array}{l}\text { des-ilusión "disappc } \\
\text { [de.si.lu.sjón] }\end{array}$ \\
\hline
\end{tabular}

As illustrated in (4), the Granada dialect presents across-the-board aspiration in prefixes, i.e. both before a consonant (des-calzar [deh.kal.sár] 'to unshoe') and

\footnotetext{
${ }^{12}$ In Lexical Phonology and similar frameworks involving a distinction between the lexical and post-lexical components, it can be assumed that syllabification and resyllabification are a part of the same algorithm that applies at the beginning of evaluation before segmental processes. Then, aspiration must be a word-level process and at the post-lexical level resyllabification is activated and followed by e.g. deletion. Such an approach was proposed e.g. by Kaisse (1999). Nevertheless, the 'resyllabification before segmental processes' approach is problematic when prefixed forms are taken into account. See the analyses in Section 3 for more details.

${ }^{13}$ This does not mean, however, that Chilean is unique in this respect. See Lipski (1996) for a dialectal overview. Also, see literature on alternative coda $s$ repairs, such as e.g. metathesis in Málaga Spanish (Vida-Castro 2015).
} 
before a vowel, regardless of resyllabification: des-hecho [de.hé.tfo] 'undone'. Other, more conservative dialects might present no aspiration at all in both cases ([des.kal.Өár] and [de.sé.t5o], respectively). Meanwhile, Chilean exhibits aspiration across a prefix boundary before a consonant, but not before a vowel. Thus, descalzar 'to unshoe' surfaces as [deh.kal.sár], while deshecho 'undone' is simply [de.sé.tfo]. ${ }^{14}$ This suggests that the otherwise licit process of coda $s$ debuccalisation is banned in prefix-stem contexts before vowels. Also, note that despite being more "conservative" in $s$ weakening in other positions (no deletion), the Granada dialect seems to be more 'innovative' than Chilean in the case of prefixed forms. In other words, prefixed items in Chilean behave like monomorphemes, whereas the same structures in Granada Spanish resemble phraselevel sequences. This is of consequence for the formal representation of $s$ weakening in each of the dialects.

\subsection{The treatment of $s$ aspiration as positional coda weakening}

I base my analysis of the Spanish data on two assumptions. First, $s$ aspiration is an instance of lenition, which is a general phenomenon reported crosslinguistically and involving a series of changes toward a simpler articulation of sounds in weak positions, along the so-called lenition trajectories (Lavoie 1996). These changes are phonetically induced (caused by the tendency of our articulators to reduce the degree of constriction and duration of sounds), and guided by such considerations as ease of production and perception. They can be both synchronic and diachronic, and lead to phonological changes (categoricity, alternations, influence on sound contrasts and on other processes). The phenomenon has been widely studied in literature (e.g. Kirchner 1998; see also Flemming 1995 for reflections on the perceptual basis of weakening). The second assumption is that the way segments behave across constituents is based on positional strength. Crucially, the syllable coda is a weak position, therefore we expect that the $s$ will be more likely to weaken in the coda than in the onset (which is indeed the case). The concept of positional strength (Casali 1996) has been studied in conjunction with lenition e.g. by Honeybone (2008) and Ségéral and Scheer (2008) who distinguish four degrees of strength: word-initial onsets, word-internal onsets, word-final codas and word-internal codas. The latter two categories are especially relevant in studying Spanish $s$.

\footnotetext{
${ }^{14}$ This is confirmed by Hernán Emilio Pérez Muñoz, a phonetician from the University of Concepción, Chile (personal communication).
} 
As noted by a reviewer, from the perceptual point of view, sibilant fricatives have robust acoustic cues and this is why they are alleged to resist changes, even in weak positions (Hayes et al. 2004; Henke et al. 2012). Nevertheless, $s$ weakening has been reported in several languages, both synchronically and diachronically (e.g. in northern varieties of French, Corsican, Babine or Ecuadorian Spanish; Gurevich 2004). This involves either debuccalisation/loss or voicing, depending on the position of $s$. The process of debuccalisation itself is also well-attested. Typically, fricatives debuccalise to [h] while stops debuccalize to [?], the motivation being articulatory simplification or feature loss rather than exchanging one set of features for another (in both cases, the consonant simply loses place and retains the continuancy specification). Such changes have been observed in Navajo, Middle Chinese, English, Tauya, Páez and other languages. Furthermore, the glottal fricative [h] can be lost in phrase- and word-final position, as in Spanish, Nepali, Newari or Nez Perce. For an overview of lenition phenomena and their motivation, see the typological work by Gurevich (2004).

Consequently, despite the perceptual salience of $s$, we are dealing with positional weakening, which can be analysed from the point of view of sonority: high sonority segments are preferred in the coda (Sievers 1876/1893; Clements 1990; Baertsch 2002). Therefore, a sonority-based harmonic scale could be assumed by which the constraint banning $s$ from the coda would be the secondhighest ranked constraint after the one banning stops (e.g. Zec's 1995 proposal). Indeed, such an approach is in line with the behaviour of Spanish obstruents, at least in the dialects discussed here. In Optimality Theoretic terms, Prince and Smolensky's harmonic scales can be applied directly in the form of constraints corresponding to the (dis)preference of particular sounds in coda position (e.g. according to the proposed margin constraint hierarchy for codas, $s$ is the second most dispreferred sound type and should be avoided). ${ }^{15}$ It must be pointed out, however, that the sonority approach to lenition has been criticized by some authors as it cannot explain certain consonantal lenition changes. The more adequate strength scales and lenition trajectories should be adopted instead, it is argued. See e.g. Honeybone (2008) and Broś (2015) for an overview of these issues.

Another perspective worth taking into account in the analysis of Spanish $s$ is the Syllable Contact Hypothesis (Vennemann 1988), according to which rising sonority across syllable boundaries is avoided and the greater the sonority slope

\footnotetext{
$15 *$ CODA / voiceless stop $>>$ CODA / voiceless fricative $>>$ CODA / voiced stop $>>*$ CO$\mathrm{DA} /$ voiced fricative $>>$ *ODA / nasal $>>$ * CODA / lateral $>>$ CODA / rhotic $>>$ CODA / glide (Prince and Smolensky 1993/2004: 127-130).
} 
between the onset and the offset of the preceding consonant the better. This has been formalized differently by different scholars (see e.g. Gouskova 2004 or Baertsch 2002). Pons-Moll (2011) presents abundant evidence from Romance languages for the fact that margin slopes tend to be respected, which should be properly expressed by analytical tools used in phonology. Indeed, the lenition of $s$ can be analysed as a response to the Syllable Contact Law in preconsonantal position. $S$ aspiration and loss can be seen as an improvement of syllabic structure in terms of sonority. Nevertheless, prevocalic structures can be analytically problematic, and the approach is not able to account for prepausal behaviour of $s$. For this reason, I will not pursue this line of reasoning further.

To summarise this subsection, I assume that $s$ changes observed in Granada and Chilean Spanish are instances of positionally-governed lenition and, in formal OT terms, repairs triggered by the coda condition against $s$ - a specific instantiation of the general coda condition constraint. Hence, in Section 3, I use *s]CODA as the markedness constraint responsible for weakening.

\subsection{A note on the underlying representations}

The data presented in (1-4) show a variety of words with internal and final $s$. Not all of these words present alternations. Typically, nouns and adjectives ending in $s$ and belonging to the group of irregular $e$-stems contain stem-final [s] alternating with $[\mathrm{h}]$ (in Granada) and $[\varnothing]$ (in Chilean). The example used in the data is the singular vez [beh] / [be] vs. the plural veces [be.seh] / [be.se] 'time(s)'. Some other words of this type include: actriz 'actress', mes 'month', inglés 'English', capaz 'capable', etc. These alternations apply to both varieties under study. Additionally, alternations can also be observed in prefixes in Chilean (desconfiar vs. deshecho, as in (4)), but not in Granada. In all other cases, it is difficult to determine whether the $s$ is underlying. Whereas in Chilean this would mean that both underlying $/ \mathrm{s} /$ and $/ \mathrm{h} /$ alternate with zero, which makes the analysis more problematic, in Granada it is possible to assume $/ \mathrm{h} /$ in the non-alternating cases. Nevertheless, I assume underlying /s/ for three reasons.

First, based on my fieldwork in Chilean and on my consultations with speakers of the Granada variety, I can assume that the /s/ is present in native speakers' minds. There is variability in the pronunciation of $s$ in careful speech, when the speaker is asked to read out a text slowly, repeat items or elicit them for a foreigner to understand (directions, etc.). From the point of view of learnability, native speakers must be exposed to the [s] variant when acquiring the language. This is probably dictated by orthography and scholarisation. 
Second, I assume Richness of the Base (Prince and Smolensky 1993/2004), according to which both options are feasible and the grammar is responsible for selecting the correct surface forms regardless of the UR.

Third, I assume a free ride approach to morphophonemic learning, following McCarthy (2005b). According to this hypothesis, learners take alternations as the basis for their learning path and generalise the discovered patterns to nonalternating items, i.e. they derive all surface forms from the underlying representations derived based on alternations (unfaithful mappings). This approach is further legitimised by recent work on Catalan, another Romance language, which demonstrated independent evidence for the free ride learning algorithm (Pons-Moll and Lloret 2014; Lloret and Pons-Moll 2016). In my analysis, I use words that present alternations whenever possible (Chilean). Otherwise, I assume underlying $/ \mathrm{s} /$.

\subsection{The treatment of prefixes and Spanish prosodic structure}

In the analysis of examples (1-4), it might be argued that no opacity is to be expected in prefixed words as the prefix is syllabified together with the stem as a single prosodic word and hence deshecho behaves like semana 'week' or quise 'I wanted' where $s$ occupies the canonical onset position and does not qualify for any weakening. The debuccalised word descalzar behaves analogically to the word esto 'this' where $s$ is syllabified as a coda, driving lenition. Such a conclusion might be satisfactory for Chilean, but other dialects present different patterns (e.g. Granada).

Note that the resulting mismatch cannot be explained by solving the problematic status of the prefix. Indeed, Spanish prefixes do tend to behave differently than other affixes and have been considered to be separate prosodic words or 'domains' by some linguists (e.g. Wiltshire 1999, ${ }^{16}$ but also Face 2002, Shepherd 2003), but their accounts fail to present a uniform explanation for the diverse distributions of the fricative and its allophones across the Spanish varieties.

Another problem related to the treatment of Spanish prefixes lies in their place in the derivational hierarchy. Assuming a derivational (or stratal) approach, one must allocate them elsewhere than at the stem level. Whether they

\footnotetext{
${ }^{16}$ Following Peperkamp (1997), she proposes that a PW node intervene between the prefix and the stem, which would account for the striking similarity in the behaviour of sounds across a prefix and a word boundary (not only aspiration, but also other phonological phenomena, e.g. $e$ epenthesis). This approach will be partially pursued here.
} 
are attached at the same level as other affixes is another issue that shall not be further pursued here. What must be taken into account, however, is the similarity in the behaviour of prefixes and phonological words, at least in some dialects. Compare, for instance, the word deshecho [de.hé.tfo] 'undone' with the sequence las ocho [la.hó.t5o] 'eight o'clock' in the Granada dialect. Both present the same syllabification and debuccalisaton, suggesting a single driver for the process. At the same time, the prefix cannot resyllabify with the stem until the process of debuccalisation has applied, otherwise there is no motivation for it. Given that resyllabification must be post-lexical to generate debuccalised $[\mathrm{h}]$ in las ocho [la.hó.tfo] in the dialect, the prefix must be assigned special status or deemed a different grammatical category. In a dialect which blocks debuccalisation across a prefix boundary before a vowel, on the other hand, the prefix behaves as any other affix in that it resyllabifies and leaves the fricative unaffected ([de.sé.t $\left.\int 0\right]$ in Chilean). Here, the prefix seems not to enter the phrase level category, which makes it difficult to provide a uniform analysis of all the cases encountered across the Spanish dialects: why would the prefix have a different status for the purposes of one specific phonological process only? I try to resolve this issue in the next sections by resorting to the notion of contiguity and extending it to the supramorphemic level. Most importantly, however, I base my phonological analysis on the assumption that prosodic structure is the same for all Spanish dialects and strictly dependent on the morphological makeup of words. At the same time, prosodic mismatch (misalignment between the stem/morphological word and the prosodic word) obtains in phrase-level phonology, as well as in prefixed forms. Thus, the representational difference between the dialects discussed here lies in the resyllabification across a prefix boundary, which happens at the word level in Chilean, and at the phrase level in Granada, hence the similarity in the behaviour of prefixed words and word sequences in the latter. Also, since Granada admits optional deletion in some variants, postulating a different prosodic structure, e.g. that the prefix is a separate prosodic word, is not a viable option. With this assumption in mind, let us look at the morphological structure of Spanish words presented below. ${ }^{17}$

\footnotetext{
${ }^{17}$ I follow Torres-Tamarit $(2012,2014)$ in assuming that morphology precedes phonology by arranging roots and affixes hierarchically. Stems are built successively, the end result of which is the Morphological Word, "the linguistic unit of analysis whose integrating parts are unable to be manipulated by syntax" (Torres-Tamarit 2012: 118). At the same time, prosodic constituents create opaque domains in phonology. Thus, opacity can be attributed to the mismatch between morphological and prosodic structures.
} 


\begin{tabular}{|c|c|c|}
\hline individual words (sg) & vez 'time' & {$\left[\left[\text { vez }_{\text {Root }}\right] \varnothing\right]_{\text {Stem }=M W d}$} \\
\hline affixed words (inflection) & veces 'times' & {$\left[\left[\left[\left[\mathrm{vez}_{\text {Root }}\right]-\mathrm{e}\right]_{\text {Stem }}\right]-\mathrm{s}\right]_{\mathrm{MWd}}$} \\
\hline words (derivation) & carita 'face' diminutive & {$\left[\left[\text { car }_{\text {Root }}\right]-\text { ita }\right]_{\text {Stem }=M W d}$} \\
\hline xed words (prefixes) & descalzar 'to unshoe' & {$\left[\text { des- }\left[\left[\text { calz }{ }_{\text {Root }}\right]-\operatorname{ar}\right]_{\text {Stem }}\right]_{\mathrm{MWd}}$} \\
\hline & deshacer 'undo' & {$\left[\mathrm{des}-\left[\left[\mathrm{hac}_{\text {Root }}\right]-\mathrm{er}\right]_{\mathrm{Stem}}\right]_{\mathrm{MWd}}$} \\
\hline $\mathrm{d}$ sequences & esa cara 'that face' & $\begin{array}{l}{\left[\left[\mathrm{eS}_{\text {Root }}\right]-\mathrm{a}\right]_{\text {Stem }}=\mathrm{MWd}} \\
{\left[\left[\mathrm{car}_{\text {Root }}\right]-\mathrm{a}\right]_{\text {Stem }}=\mathrm{MWd}}\end{array}$ \\
\hline
\end{tabular}

Against this background, the resultant prosodic structure may or may not match morphological concatenation. Following Bermúdez-Otero (2013) and others, I assume that certain affixes are root-based in Spanish, whereas others are stembased. In Stratal OT this means that affixes can be attached at different derivational levels. Given the behaviour of prefixes in combination with aspiration, and with $e$-epenthesis (Peperkamp 1997), as well as the fact that they attach to independent words (Harris and Kaisse 1999) and have null impact on stress, I assume that they attach at the word level and are then subject to resyllabification against the underlying morphology. As a result, the word deshecho is syllabified de.she.cho, just as sequences of words are resyllabified together to form new prosodic words, e.g. es asi 'it's like this' syllabified e.sa.sí. At the same time, it must be remembered that in Stratal OT prosodic structure is erected at the first (stem) level and only then restructured in accordance with the grammar (the constraint hierarchy). As will be demonstrated in the remaining sections, differences in the constraint ranking account for the different behaviour of $s$ across dialects. The prosodic structure of Spanish is presented in (6) below.

As illustrated in (6), prosodic structure does not necessarily coincide with the morphological makeup of the words in question (compare with the examples in (5)). For individual words in phrase phonology, I assume that the prosodic structure is assigned individually for each word (Pw node), and then later on changed due to resyllabification (misaligned with the edge of the stem). This is exemplified in Optimality Theoretic terms in Section 3. As for the prefixed forms, the base is a stem analysed in stem-level phonology and

\footnotetext{
${ }^{18} \varnothing,-e$ and $-a$ are class markers. The morphological structure is based on spelling.
} 
(6) Spanish prosodic structure (based on Chilean pronunciations)

\begin{tabular}{|c|c|c|c|c|}
\hline (a) stem level & & (b) phrase & level & \\
\hline 'time' & $(b e h)_{\mathrm{PW}}$ & vez & 'time' & $(\mathrm{be})_{\mathrm{Pw}}$ \\
\hline comí & (ko.mí) $)_{\mathrm{Pw}}$ & vez comí & 'time I ate' & (bé $)_{\mathrm{Pw}}(\text { ko.mí) })_{\mathrm{Pw}}$ \\
\hline 'entered' & $(\text { en.tré })_{\mathrm{Pw}}$ & vez entré & 'time I entere & $(\text { bé })_{\mathrm{Pw}}(\text { hen.tré })_{\mathrm{Pw}}$ \\
\hline calzar 'sho€ & $(\text { kal.sár })_{\mathrm{Pw}}$ & descalzar & 'unshoe' & $\left.(\text { deh.(kal.sár })_{\mathrm{Pw}_{\mathrm{Pw}}}\right)_{\mathrm{Pw}}$ \\
\hline tacer 'do' & $(\text { a.sér })_{\mathrm{Pw}}$ & deshacer & 'undo' & $\left.(\text { de.(sa.sér })_{\mathrm{Pw}}\right)_{\mathrm{Pw}^{\prime}}$ \\
\hline
\end{tabular}

hence parsed as a prosodic word. At the word level, when the prefix is added, another prosodic word is erected ( $\mathrm{PW}^{\prime}$ ) that corresponds to the edges of the whole morphological word. ${ }^{19}$ Resyllabification and PW restructuring ensues either at the same level or at the phrase level, depending on the dialect. This is illustrated in section 3. Prosodic structure assignment is governed by alignment constraints: ALIGN-L(Morphological Word, Prosodic Word) and ALIGN-L(Stem, Prosodic Word). Provided that the Morphological Word is a higher-level constituent (as in example 5), the former constraint must be ranked above the latter to ensure the erection of the $\mathrm{PW}$ ' node. ${ }^{20}$

\subsection{The role of contiguity}

It must be noted that regardless of the variety, $\mathrm{S}$ does not admit uncompensated word-internal deletion. ${ }^{21}$ At the same time, deletion is quite common wordfinally before a pause and across word boundaries (as in Chilean). Such a state of affairs seems to suggest that word-internal segments receive special protection as opposed to word edges, which can be explained by the notion of morpheme contiguity. Within the OT framework, this principle has been formulated as follows.

\footnotetext{
${ }^{19}$ This is in line with Peperkamp's (1997) and Wiltshire's (2002) prosodification principles.

${ }^{20}$ The inner prosodic word in prefixed forms can be misaligned with the stem, thus Align-L(Stem, $\mathrm{Pw}$ ) is violated in this case. I would like to thank an anonymous reviewer for pointing out the importance of clarifying this issue.

${ }^{21}$ There are cases of $s$ deletion word-internally with accompanying preaspiration or gemination of the following stop (see e.g. Morris 2000). No complete feature deletion has been attested so far to the best of my knowledge.
} 


\section{CONTIGUITY:}

Segments adjacent in the input should be adjacent in the output. (Kenstowicz 1994) $^{22}$

At this point, it is worth examining the exact definition of CONTIGUITY, which is quite problematic in OT. Initially, it was introduced as a constraint banning nonedge deletion and insertion in reduplicative languages. It was later extended to input-output correspondence relations, and although its definition does not mention any morphemic restriction, it has been traditionally treated as referring to morpheme contiguity. Although the need for such a constraint has been demonstrated in a variety of cases across different languages, the grammatical interpretation of its scope has not been taken up so far in the literature, with perhaps one exception (Lamontagne 1997). Thus, a theoretical debate over its domains of application would be desirable. This article aims at exploring this issue further with the analysis of the Spanish data. For the time being, it suffices to say that contiguity seems to play an important role in Spanish. On the one hand, it bans $s$ elision in word-medial contexts, as in esto [eh.to] 'this' versus es que [e.ke] 'that is' in phrase phonology in Chilean. On the other hand, epenthetic processes confirm its relevance in initial contexts. The well-known process of $e$-epenthesis ${ }^{23}$ applies as a repair strategy to break illicit $s C$ clusters, e.g. estrategia [es.tra.té. xja] 'strategy' or eslavo [es.lá.ßo] 'Slav'. Note that the epenthetic vowel helps create an additional syllable to which the illicit $s$ attaches as a coda - an apparently nonoptimal strategy when confronted with inserting the $e$ after the initial $s$ to form a more optimal CV syllable as in *[se.tra.té.xja]. Given the fact that codas are strongly dispreferred in Spanish, the latter strategy would be more desirable were it not for the fact that it violates CONTIGUITY. This is further evidence for the higher status and strength of morpheme-internal positions as opposed to the weaker edges (which dates back to Trubetzkoy 1939; cf. Beckman 1999).

What is more, as illustrated by the data presented in Section 2, deletion is avoided across a prefix boundary in dialects permitting this strategy at word edges (desconfiado [deh.kom.fjá.ðo] 'suspicious' vs. es cómodo [e.kó.mo.ðo] 'is comfortable'). This means that contiguity is respected also across morpheme boundaries, not only within morphemes. Given this observation, I suggest that the domain of contiguity should be extended to prosodic words, which is further discussed and illustrated in a tableau in Section 3.

\footnotetext{
${ }^{22}$ I use Kenstowicz's simple definition, which can be interpreted as both no intrusion and no skipping in the sense of McCarthy and Prince's (1995: 55) definitions of input and output contiguity. ${ }^{23}$ E.g. Harris (1983).
} 


\section{Stratal OT analysis of Chilean aspiration and deletion}

In this section, I present a Stratal OT account of the data presented in (1-4).

As is well-known, Stratal OT is a modified version of the strictly parallel Optimality Theory model (Prince and Smolensky 1993; McCarthy and Prince 1995) which introduces a series of morphophonologically grounded evaluation levels involving a crucial constraint reranking. Based on the insight of Lexical Phonology (Kiparsky 1982a, 1982b; Booij and Rubach 1987) and Kiparsky's work in OT, I assume a three-level OT grammar: the stem, the word and the phrase - each with a separate phonology. At each of these levels, a different constraint hierarchy is assumed. Otherwise, the candidates undergo a parallel evaluation and the optimal candidate is chosen as the base of the subsequent level of the final output (surface form). Two levels are relevant for the present analysis: the word and the phrase.

In order to demonstrate how Stratal OT deals with the presented data, let us introduce a set of basic constraints to be used in evaluations. Only those constraints which are relevant for the portion of phonology analysed in this paper will be taken into account.

OT constraints for word-level phonology

MAX(Seg) Assign a violation mark for each deletion of a segment with respect to the input.

*S]CODA Assign a violation mark for each $s$ in the coda.

IDENT(PL) Assign a violation mark for each output segment whose input correspondent has a different place specification (following McCarthy 2008a). ${ }^{24}$

ONSET Assign a violation mark for each syllable which does not have an onset.

\footnotetext{
${ }^{24}$ An anonymous reviewer points out that the definition of place identity is crucial for the success of the OT analysis. Note that IDENT(PL) should be used in this case rather than MAX(PL). The latter would assume that features are autosegments and therefore the deletion of a segment would imply a violation of all the relevant MAX(feature) constraints. Instead, I assume that features are attributes of segments and therefore the deletion of $s$ yields vacuous satisfaction of IDENT(PL) - there is no output correspondent of the input segment to compare feature specifications with. I would like to thank the reviewer for pointing out the relevance of feature treatment in OT and its consequences for Correspondence Theory, as discussed at length by McCarthy (2008a) and others.
} 
The interactions between the above constraints account for the processes of the sort presented in the Chilean data. Thus, not only debuccalisation, but also deletion, which means that the markedness constraint banning $s$ from the coda will have a set of two repair strategies, a milder (debuccalisation) and a more radical one (deletion). Each repair is ensured by the lower ranking of faithfulness constraints, i.e. IDENT(PL) and MAX(Seg), with respect to *s]CODA. At the same time, CONTIG ensures that the first and not the second strategy is chosen wordinternally. A sample evaluation is presented in the tableau.

(9) Evaluation of the Chilean word escondidos [eh.kon.di.ðo], plural for 'hidden'

\begin{tabular}{|l|c:c|c|c|}
\hline /escondidos/ & *s]CODA & CONTIG & IDENT(PL) & MAX(Seg) \\
\hline a. ${ }^{\circ}$ eh.kon.dí.ðo & & & $*$ & $*$ \\
\hline b. e.kon.dí.ðo & & $* !$ & & $* *$ \\
\hline c. eh.kon.dí.ðoh & & & $* * !$ & \\
\hline d. es.kon.dí.ðos & $* * !$ & & & \\
\hline
\end{tabular}

*s]CODA ensures that a repair strategy is chosen instead of rendering faithful $s$ on the surface, as it would be more costly given the constraint hierarchy. CONTIG prevents deletion word-internally, hence [h] as opposed to word-final elision. $^{25}$

Based on single words, it might be concluded that IDENT(PL) and MAX(Seg) are responsible for alternative processes and might remain unranked with respect to each other, but note that ranking $\operatorname{MAX}(\mathrm{Seg})$ above IDENT(PL) would make (9c) the winner, rendering deletion virtually impossible. Meanwhile, Chilean examples suggest that the dialect admits quite radical changes, allowing for total segment loss unless this would result in the disruption of morpheme contiguity. Thus, the candidate presenting word-final deletion but word-internal aspiration is selected as optimal. This is fully in line with the Chilean data presented in Section 2.

\footnotetext{
${ }^{25}$ Note that in this case debuccalisation is equivalent to losing place features and violates the identity constraint responsible for place. Any other change would imply a violation of more than one faithfulness constraint (e.g. debuccalisation to a glottal stop, manner assimilation, gliding or lenition to $r$, which was analysed e.g. by Pons-Moll (2011) in Majorcan Catalan).
} 
At the same time, it must be noted that aspiration is strictly limited to codas. Onsets are protected at all times (e.g. semana 'week' or queso 'cheese'). The onset maximization rule expressed by the high-ranked ONSET constraint ensures that prevocalic $s$ be syllabified with the following syllable. In this way, pairs of alternating forms are created in the language - compare the singular and plural forms vez [be] 'time' and veces [be.se] 'times' in which the root is realised with or without the final $s$, depending on whether it is realised in isolation or as a part of an inflected plural form. This is also an argument for positing aspiration at the word and not at the stem level.

(10) Evaluation of the Chilean words vez and veces 'time(s)'

\begin{tabular}{|l|c|c|c|c|c|}
\hline i. $/$ bes/ & ONSET & $*$ s]CODA & CONTIG & IDENT(PL) & MAX(Seg) \\
\hline a. be & & & & & $*$ \\
\hline b. beh & & & & $* !$ & \\
\hline d. bes & & $* !$ & & & \\
\hline ii. $/$ bes+es/ & & & & & \\
\hline a. ${ }^{\circ}$ be.se & & & & & $*$ \\
\hline b. be.seh & & & & $* !$ & \\
\hline c. beh.eh & $* !$ & & & $* *$ & \\
\hline d. beh.e & $* !$ & & & & \\
\hline e. be.he & & & & $* !$ & $*$ \\
\hline f. be.ses & & $* !$ & & & \\
\hline
\end{tabular}

As illustrated in (10), ONSET plays a role in word phonology. Different syllabifications are responsible for the existence of alternations (deleted vs. nondeleted $s$ ). At the same time, $\operatorname{MAX}(\mathrm{Seg})$ has to be ranked low, and certainly lower than IDENT(PL). Otherwise candidates with aspiration would have priority over the ones without it. Gratuitous violations of IDENT(PL) are penalized: (10.ii.e) has a superset of violations with respect to candidate (10.ii.a), and therefore cannot win under any ranking. 
At the phrase level, we find further evidence for the low ranking of $\operatorname{MAX}(\mathrm{Seg})$, which ensures segment deletion before a consonant. The relevant evaluation is presented below.

(11) Evaluation of the Chilean phrase una vez comí 'once I ate'

\begin{tabular}{|c|c|c|c|c|}
\hline /una + bes + komi/ & *s]CODA & CONTIG & IDENT(PL) & MAX(SEG) \\
\hline a. u.na.ßé.ko.mí & & & & * \\
\hline b. u.na.ßés.ko.mí & *! & & & \\
\hline c. u.na.ßéh.ko.mí & & & $* !$ & \\
\hline
\end{tabular}

Note that CONTIG does not play a role in this context - it does not protect the edges of constituents in any way. Instead, the optimal strategy chosen to deal with the illicit coda $s$ is deletion and candidate (11a) becomes the winner.

In such cases, however, resyllabification does not apply because the onset position of the following word is already filled. Before a vowel, as in the phrase una vez entré 'once I entered', Chilean exhibits an opaque effect: both resyllabification and aspiration, but not deletion, apply. A proper account of resyllabification requires the activation of the following constraints.

Phrase-level constraints

ONSET

ALIGN-L(Stem, $\sigma) \quad$ Assign a violation mark if the left edge of the stem does not coincide with the left edge of the syllable.

In OT, resyllabification cannot be expressed otherwise than in terms of alignment. The requirement that the left edge of the stem coincide with the left edge of the syllable is equivalent to banning resyllabification across word boundaries. To counteract such a state of affairs, ONSET must be ranked higher. In this way, empty onset positions are filled and both marked structures: final codas and bare 
nuclei are avoided. This is a phrase-level process and therefore must be incorporated in the evaluation of Spanish phrases. The table in (13) presents a simple case of resyllabification without the additional complication in the form of opaque aspiration.

(13) Evaluation of estas alas [es.ta.sa.las] 'these wings' as produced in a non-aspirating dialect

\begin{tabular}{|l|c|c|}
\hline$/$ estas + alas/ & ONSET & ALIGN-L(Stem, $\sigma$ ) \\
\hline a. (és.ta).(sá.las) & & $*$ \\
\hline b. (és.tas).(á.las) & $* !$ & \\
\hline
\end{tabular}

In the above tableau, candidate (13b) is eliminated as it violates the higherranked constraint (ONSET). Forming a licit onset whenever possible is therefore more important in Spanish (across all dialects) than misaligning the stem with the syllable. Adding a complication in the form of aspiration to the tableau is problematic in standard OT, however. This is illustrated in (14).

(14) Evaluation of the Chilean phrase una vez entré [u.na.ßé.hen.tı̇é] 'once I entered'

\begin{tabular}{|c|c|c|c|c|c|}
\hline /una + bes + entre/ & ONSET & $*$ s]CODA & $\begin{array}{l}\text { ALIGN-L } \\
(\text { Stem, } \sigma)\end{array}$ & IDENT(PL) & $\operatorname{MAX}(\mathrm{Seg})$ \\
\hline a. (u.na).(ßé).(sen.tıé) & $*$ & & $*$ & & \\
\hline b. : (u.na).(ßé).(hen.tı́é) & $*$ & & $*$ & $* !$ & \\
\hline c. (u.na).(ßé).(en.tı́̃ & $* * !$ & & & & $*$ \\
\hline d. (u.na).(ßés).(en.tı̊é) & $* * !$ & $*$ & & & \\
\hline e. (u.na).(ßéh).(en.tıó) & $* * !$ & & & $*$ & \\
\hline
\end{tabular}

As illustrated in (14), standard OT is unable to account for aspiration in interaction with resyllabification. *s]CODA plays no role in the evaluation as the input 
$s$ is resyllabified as the onset of the word entré. Since the segment does not occupy the coda position, the markedness constraint is inactive. Candidate (14a) wins the battle. The actual output, candidate (14b), is rejected due to the violation of IDENT(PL) (there is a tie on ALIGN-L). Note that the output of $s$ aspiration cannot be treated as the coda of the first word because of the high-ranked ONSET, which ensures that codas are properly resyllabified into the empty onset positions. Thus, candidate (14e) is eliminated, whereas word-final $s$ deletion, the default strategy in prepausal and preconsonantal contexts, is the worst result of all as it does not improve on ONSET requirements (the highest-ranked constraint) and additionally violates $\operatorname{MAX}(\mathrm{Seg})$, thereby introducing a more marked structure than initially encountered. A proper account of Chilean opacity must therefore include a derivational level that would introduce a remnant of pre-OT rule ordering, i.e. ensure that aspiration applies at the word level and resyllabification afterwards, at the phrase level. This is possible under the Stratal OT framework. Thus, given the two repair strategies used to satisfy the coda condition against $s$ in Chilean, the most logical approach consists in postulating word level aspiration followed by deletion at the phrase level. With this in mind, $\operatorname{MAX}(\mathrm{Seg})$ must be ranked higher than IDENT(PL) at the word level to ensure aspiration instead of deletion as the most optimal coda condition repair. *S]CODA must be ranked the highest as the assumed aspiration driver.

Word level aspiration in Chilean: vez /bes/ 'time'

\begin{tabular}{|l|c|c|c|}
\hline$/$ bes/ & ${ }^{*}$ S]CODA & MAX(Seg) & IDENT(PL) \\
\hline a. béh & & & $*$ \\
\hline b. bés & $* !$ & & \\
\hline c. bé & & $* !$ & \\
\hline
\end{tabular}

Drawing on the generalisations made in the previous sections, the next stage, i.e. phrase level phonology, requires either the retention of $[\mathrm{h}]$ before a vowel as in una vez entré 'once I entered' or its deletion before a consonant or a pause as in una vez comi 'once I ate', vez 'time', as well as plural veces 'times'. The former is ensured by ONSET. 
(16) Phrase level [h] retention before a vowel in Chilean: una vez entré 'once I entered' 26

\begin{tabular}{|c|c|c|c|c|}
\hline /u.na + beh + en.tre/ & ONSET & *s]CODA & $\operatorname{MAX}(\mathrm{Seg})$ & IDENT(PL) \\
\hline a. (u.na).( $\beta$ é).(hen.tré) & $*$ & & & \\
\hline b. (u.na).(ßé).(sen.tré) & $*$ & & & $* !$ \\
\hline c. (u.na).(ßé).(en.tré) & $* * !$ & & * & \\
\hline
\end{tabular}

Note that in (16), the winning candidate presents maximal faithfulness, thus no change compared to the input structure except for syllabification. This is crucial for the analysis: the candidate preserving the $[\mathrm{h}]$ from the input will always win, even if we rerank IDENT(PL) and MAX(Seg) with respect to each other to ensure deletion with such inputs as /una + beh + komi/ (cf. example 17). The following tableau demonstrates, however, that it is impossible to generate deletion in the case of an aspirated input produced at the word level under any ranking of the constraints.

(17) Phrase level deletion before a consonant in Chilean: una vez comi 'once I ate'

\begin{tabular}{|c|c|c|c|}
\hline /u.na + beh + ko.mi/ & *s]CODA & IDENT(PL) & $\operatorname{MAX}(\operatorname{Seg})$ \\
\hline \multicolumn{4}{|l|}{ a. (u.na).(ßéh).(ko.mí) } \\
\hline b. (u.na).(ßés).(ko.mí) & $* !$ & $*$ & \\
\hline c. : (u.na).(ßé).(ko.mí) & & & $* !$ \\
\hline
\end{tabular}

In (17), the ranking of IDENT(PL) and $\operatorname{MAX}(\mathrm{Seg})$ is reversed. Thus, we have *S]CODA $>>\operatorname{IDENT}(\mathrm{PL})>>\operatorname{MAX}(\mathrm{Seg})$. Despite this operation, however, the undesired candidate is chosen as optimal as it does not offend any of the constraints.

\footnotetext{
${ }^{26}$ Note that the output of (15) is now the input to (16), together with the other two words. Syllabification is added at the word level, thus it is already present in the input to the phrase level. The three words which now constitute the input were generated independently at the word level.
} 
$\operatorname{IDENT}(\mathrm{PL})$ plays no role in the choice between the aspirated candidate and the one presenting deletion. Due to the change of the input candidate, (17a) does not violate IDENT(PL) which would otherwise eliminate it in favour of (17c) assuming the ranking IDENT(PL) $>>\operatorname{MAX}(\mathrm{Seg})$. What is more, with the present configuration, $\left.{ }^{*} \mathrm{~s}\right] \mathrm{CODA}$ is no longer the trigger of coda deletion. Because $s$ undergoes aspiration at the word level, *S]CODA is unable to take an active part in candidate evaluation later on. It seems that the segment barred from the coda is [h]. It is deleted in vez and una vez comí, where it occupies the coda position, and retained in the onset (una vez entré, una vez es demasiado) or when saved by CONTIG (esto). Based on this asymmetry, it can be postulated that the segment inventory constraint barring $[\mathrm{h}]$ from surfacing in the output is at play. Let us then incorporate *h ("don't be [h]") into the tableau.

(18) Final phrase level evaluation with coda deletion in Chilean

\begin{tabular}{|l|c:c|c|c|c|}
\hline /u.na + beh + ko.mi/ & ONSET & $*$ S]CODA & IDENT(PL) & $* \mathrm{~h}$ & MAX(Seg) \\
\hline a. (u.na).(ßé).(ko.mí) & $*$ & & & & $*$ \\
\hline b. (u.na).(ßéh).(ko.mí) & $*$ & & & $* !$ & \\
\hline
\end{tabular}

As demonstrated in (18), ${ }^{*} \mathrm{~h}$ - a segment inventory constraint crucially present in the grammar regardless of the existence of other types of markedness constraints - is able to deal with all the problematic cases under analysis and it is clear that its role in Chilean phonology is crucial. Nevertheless, this does not diminish the contribution of *S]CODA. In fact, both of these markedness constraints are needed in the Chilean Spanish grammar to account for the presented data. *h ensures the correct evaluation at the phrase level, while *s]CODA is indispensable at the word level. Chilean must rank the latter constraint high because only syllable-final $s$ is affected in non-opaque cases. Onset $s$ remains untouched, e.g. semana 'week', quise 'I wanted' or asombroso 'astonishing' cannot have anything else but $s$ on the surface. Word-medial instances of coda $s$ aspiration only confirm this fact, and if we rejected *s]CoDA altogether or demoted it to an irrelevant, low-ranked position, we would be forced to postulate onset $s$ aspiration in the opaque cases (e.g. una vez entré). 


\subsection{Prefix treatment in Chilean under Stratal OT}

After establishing the path of rendering the correct surface forms in the aspirating/deleting Chilean dialect, it is now time to determine how to deal with prefixed words. Note that in Chilean prefixed words behave like single morphemes in that no aspiration applies across a prefix boundary before a vowel. Thus, they cannot be analysed as sequences of words where aspiration applies. At the same time, the ban on coda $s$ remains active in that prefix-final fricatives are aspirated before a consonant, but not deleted as in una vez comí. Therefore, the data confirm that prefixes do not behave like separate prosodic words or 'special domains' of any kind. Rather, in accordance with the proposed prosodic and morphological structure of Spanish prefixes (examples 5 and 6), they form part of a bigger constituent as bound morphemes. In prosodic terms, this is expressed in the form of a recursive prosodic word domain.

Given the Stratal OT analysis presented in the previous section, prefixes become problematic at the phrase level. The word level renders aspirated $s([\mathrm{~h}])$, which cannot be protected from deletion. Thus, whereas a pre-vowel case of prefixation is neatly solved by syllabification at the word level, pre-consonantal cases escape this solution. Let us illustrate this in a tableau.

Word-level evaluation of deshecho 'undone'

\begin{tabular}{|c|c|c|c|c|c|c|c|}
\hline$/ \mathrm{des}+\mathrm{et} \mathrm{do} /$ & ONSET & $\begin{array}{l}\text { CONTIG } \\
\end{array}$ & i*s]CODA & ALIGN-L & $\operatorname{MAX}(\operatorname{Seg})$ & $\operatorname{IDENT}(\mathrm{PL})$ & $* \mathrm{~h}$ \\
\hline a. (de.(sé.tfo)) & & & & $*$ & & & \\
\hline b. (de.(hé.tfo)) & & & 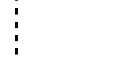 & $*$ & & $* !$ & $*$ \\
\hline c. $($ des.(é.tfo $))$ & $* !$ & & $*$ & & & & \\
\hline d. (deh.(é.tfo)) & $* !$ & & & & & $*$ & * \\
\hline e. (de.(é.t $\left.\left.\int o\right)\right)$ & $* !$ & & : & & * & & \\
\hline
\end{tabular}

As demonstrated in (19), all cases of non-syllabification of the prefix with the stem result in a fatal violation of the highest-ranked constraint, while aspiration requires an additional, unnecessary violation of identity, thus the simply misaligned candidate (19a) is selected as optimal. Under such an analysis, however, descalzar 'to unshoe' would leave the word level with a debuccalised segment 
as the input to the phrase level: (deh.(kal.sár)) - here, syllabification is not an obstacle as the onset position is already filled in the stem (calzár); $s$ is obligatorily in the coda and has to debuccalise to satisfy *s]CODA. The desired phrase level candidate cannot surface under such an analysis: deletion is produced similarly to phrases such as una vez comi 'once I ate' although the placeless [h] should be retained. This is illustrated by the tableau in (20). Unsuccessful phrase evaluation of descalzar 'to unshoe'

\begin{tabular}{|l|c:c|c:c|c|c|}
\hline$/$ deh + kal.sar/ & CONTIG & **s]CODA & ALIGN-L & IDENT(PL) & $*$ h & MAX(Seg) \\
\hline a.:(deh.(kal.sár)) & & & & & $* !$ & \\
\hline b. (des.(kal.sár)) & & $* !$ & & $*$ & & \\
\hline c. (de.(kal.sár)) & & & & & & $*$ \\
\hline
\end{tabular}

Note that CONTIG does not protect descalzar in this case: it does not assign a violation mark to (20c) because of the morpheme boundary that intervenes between the prefix and the stem. As pointed out earlier, however, the exact definition of CONTIG is problematic in OT. Although it does not explicitly mention any morphemic restriction, it has been traditionally treated as referring to morphemes. Nonetheless, the Chilean case demonstrates that the grammar treats a prefixed word as a whole, barring deletion across a prefix boundary as if it were one morpheme. In this respect, prefixed words are treated in the same way as bare stems and suffixed words - they belong to the 'word' domain, which does not allow internal interference in the form of segment deletion. Elision of the underlying $s$ is possible only at word edges (either before a pause or before a consonant-initial word). Inside words, aspiration is the last stage of $s$ weakening. This is ensured precisely by CONTIG (cf. the word escondidos 'hidden' in example 9). To ensure that the same restriction is preserved in prefixed words, CONTIG must refer to the whole prosodic word.

(21) CONTIG]PW: No deletion/insertion in the middle of a prosodic word. (adapted from Rubach 2011) 
CONTIG]PW ensures that the input string is identical to the output structure in that no deletion or insertion takes place within it, protecting word-medial segments but not the edges. Such a constraint has already been proposed by Rubach (2011) to address insertion problems in Macedonian. Crucially, Rubach pointed to the problematic behaviour and status of clitics in this language, and to the need for a constraint that protects word-medial structures and mandates schwa insertion at the edge of the stem rather than inside it in both prefixed and nonprefixed words. Due to the fact that clitics do not form part of the PW in Macedonian, cliticised structures can exhibit internal insertion when analysed as a whole, but always at the prosodic word edge. This constitutes an important insight into the role prosodic domains higher than the syllable play in the analysis of phonological processes. The present analysis adds evidence from deletion to the evidence from insertion provided by Rubach.

Note that reference to prosodic structure is not problematic from the Stratal OT perspective as prosodic structure is erected at the first derivational level. The phrase level already contains information concerning prosodic word parsing at the level of the input. As argued in the previous sections, prosodic word structure is erected in the stem calzar 'to shoe', followed by the PW' node after prefixation. With CONTIG]PW in place, the evaluation of descalzar at the phrase level no longer poses a problem.

(22) Evaluation of descalzar 'to unshoe' with the use of CONTIG]PW

\begin{tabular}{|c|c|c|c|c|c|c|c|c|}
\hline /deh + kal.sar/ & ONSET: & SSG: & CONTIG]PW & *s]CODA & ALIGN-L & $\begin{array}{c}\text { IDENT } \\
(\mathrm{PL})\end{array}$ & $* \mathrm{~h}$ & $\begin{array}{l}\text { MAX } \\
\text { (Seg) }\end{array}$ \\
\hline a. $\odot$ (deh.(kal.sár)) & & & & & & & $*$ & \\
\hline b. (de.(hkal.sár)) & & $* !$ & & & * & & $*$ & \\
\hline c. (des.(kal.sár)) & 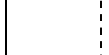 & & & $* !$ & & $*$ & & \\
\hline d. (de.(skal.sár)) & & $* !$ & & & * & $*$ & & \\
\hline e. (de.(kal.sár)) & ; & & $* !$ & & & & & $*$ \\
\hline
\end{tabular}

In (22), the correct output form is generated. (22e) is eliminated by CONTIG]PW. $(22 \mathrm{c})$ is defeated by *S]CODA. The other two candidates are suboptimal due to $\mathrm{SSG}$, which requires that the sonority of segments rise toward the nucleus of the 
syllable. ${ }^{27}$ (22a) surfaces as optimal as it violates only the lower-ranked $* h$. Thus, the provided constraint ranking is able to account for all the Chilean examples, including prefixed words. With respect to the latter, note that treating prefixes as an integral part of the word in question (at least in prosodic terms) is the only viable option. No recourse can be made to morphology. One might suggest that prefixes are added at a different stage of phonology, alluding to their supposed special status in several languages, including English with its level 1 and level 2 affixes. Nevertheless, it results impossible to remove the obstacle in this case. Whether we add the prefix des-at the very beginning or at the end is irrelevant. The reason for such a state of affairs is simple: it is not the base (stem) that undergoes the change in question but the prefix itself; the stem remains unaffected. At the same time, the prefix is no solution in itself. The key to the analysis of Chilean aspiration and deletion effects is the prefixed word as a whole, apparently treated as one contiguous string resistant to deletion. This is effected by CONTIG]PW. ${ }^{28}$

A reviewer points out that the prosodic structure of cliticised phrases as opposed to prefixed words should be discussed. Given the fact that Spanish prefixes have been argued to act like clitics, word sequences consisting of unstressed function words followed by host nouns may contradict the effect of the CONTIG]PW constraint. Note that such phrases as las normativas 'the norms' presented in (2a) above behave differently than prefixed words in Chilean. Namely, the underlying $s$ is retained as $[\mathrm{h}]$ in prefixes (e.g. descalzar) but deleted in las normativas. In the latter case, the behaviour is typical of word sequences although the first word is a bound morpheme which cannot receive stress and cannot be assigned a prosodic word status. Nevertheless, the assumption about the activity of CONTIG]PW holds as the two types of bound structures differ in the way they are prosodified. I follow Selkirk's (1995) position which dismisses intermediate constituents between the prosodic word and the phonological phrase (contra e.g. Nespor and Vogel 1986 who posit clitic structures). Selkirk assumes that function words and other bound morphemes present different prosodic

\footnotetext{
${ }^{27}$ Note that an additional constraint, SSG (Sonority Sequencing Generalisation), has been added to prevent incorrect syllabification (Jespersen 1904; Selkirk 1984). The constraint is high-ranked in Spanish (Hualde 1989).

${ }^{28}$ As pointed out by an anonymous reviewer, a possible alternative consists in a perception-driven analysis (e.g. Steriade 2001). With such an approach, direct reference to the presence of a word boundary might be made and we might assume that $[\mathrm{h}]$ is less perceptible phrase-finally. The process could be then generalised to the word-final position, and hence not all coda $[\mathrm{h}]$ segments would undergo deletion. The analysis would be similar to the account of final devoicing by Blevins (2004).
} 
structures depending on their phonological makeup, position and behaviour. The principal prosodic constituents are: syllable, foot, prosodic word, phonological phrase, and intonational phrase. They form a hierarchy and admit a special type of recursivity, e.g. in compounds and prefixed words where we have a $\mathrm{PW}^{\prime}$, as illustrated earlier. This stance is followed by e.g. Peperkamp $(1996,1997)$ and Lleó (2012). I assume that prefixes are affixed to the word and therefore attached to a recursive prosodic word node, whereas articles and similar proclitic structures, which display different behaviour (e.g. cannot form a foot together with the first syllable of their host, do not affect stress and are acquired differently by children), are attached directly to the Phonological Phrase. Thus, they do not form a PW with their hosts and the CONTIG]PW constraint does not apply to them. In Selkirk's terms, they are free clitics (whereas prefixes are affixal clit$i c s$ ). To illustrate the difference, las normativas is prosodified (las(normativas $\left.)_{\mathrm{PW}}\right)_{\mathrm{PPH}}$, as opposed to descalzar prosodified as $\left(\left(\text { des }(\text { calzar })_{\mathrm{PW}}\right)_{\mathrm{PW}}\right)_{\mathrm{PPH}}$. The specific case of articles, such as las in las normativas is discussed by Lleó (2012) in terms of prosody, with arguments from L1 acquisition.

\subsection{Prefixes in Granada-type dialects}

After providing the correct evaluation of the Chilean data, at least one important task remains to be solved. The ability to account for other Spanish dialects will further legitimise the viability of the Stratal OT account presented in this paper. Let us then examine the Granada dialect data, where aspiration occurs both across a word and a prefix boundary before a vowel. The word deshecho 'undone' is put under evaluation in (23).

(23) Word level evaluation of deshecho 'undone' with aspiration across a prefix boundary

\begin{tabular}{|c|c|c|c|c|c|c|c|}
\hline$/ \operatorname{des}+\operatorname{et} \int \mathrm{o} /$ & ALIGN-L & ONSET & CONTIG & *s]CODA & $\operatorname{MAX}(\mathrm{Seg})$ & IDENT(PL) & $* h$ \\
\hline a. (deh.(é.tfo)) & & $*$ & & & & $*$ & * \\
\hline b. (de.(hé.tfo)) & $* !$ & & & & & * & * \\
\hline c. $($ des.(é.tfo)) & & $*$ & & $* !$ & & & \\
\hline d. (de.(sé.tfo)) & $* !$ & & & & & & \\
\hline e. $($ de. $($ é.t $f \mathrm{o}))$ & & $*$ & & & $* !$ & & \\
\hline
\end{tabular}


In (23), candidate (23a) is selected as optimal. It presents aspiration in the coda. Note that the Granada dialect and the like require that resyllabification not take place at the word level. The prefix-final segment remains attached to the coda position of the first syllable. This is ensured by ALIGN-L, which is ranked above ONSET to mandate alignment. (23c) is eliminated by *S]CODA. A tie is produced in candidates (23a) and (23e) on ONSET. This is solved by MAX(Seg). Candidate (23a) surfaces as the winner and provides the input to the phrase level.

(24) Phrase level evaluation of deshecho 'undone' with aspiration across a prefix boundary

\begin{tabular}{|c|c|c|c|c|c|c|}
\hline /deh.e.tfo/ & ONSET & CONTIG $: *$ s]CODA & ALIGN-L & $\begin{array}{l}\text { MAX } \\
(\text { Seg) }\end{array}$ & $\operatorname{IDENT}(\mathrm{PL})$ & $* \mathrm{~h}$ \\
\hline a. $\sigma^{\circ}$ (de.(hé.tfo)) & & & $*$ & & & $*$ \\
\hline b. (de.(sé.tfo)) & & i & $*$ & & $* !$ & \\
\hline c. $($ des.(é.tfo)) & $* !$ & $*$ & & & $*$ & \\
\hline d. (deh.(é.tfo)) & $* !$ & 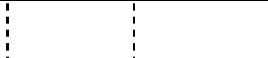 & & & & $*$ \\
\hline e. (de.(é.tfo)) & $* !$ & $i$ & & $*$ & & \\
\hline
\end{tabular}

In (24), the desired candidate is chosen as optimal. Although (24a) ties with (24b) on ALIGN-L, (24b) is eliminated by the next constraint in the hierarchy IDENT(PL). Candidates ( $24 \mathrm{c}-\mathrm{e})$ are eliminated by ONSET. Note that ALIGN-L is demoted below ONSET at the phrase level to ensure resyllabification. At the same time, $\operatorname{MAX}(\mathrm{Seg})$ stays in the same place, given that the Granada dialect does not allow deletion as a coda $s$ weakening strategy. Consequently, the provided mechanism is able to account for all the presented cases, including the most problematic ones.

4. Discussion and alternative accounts

Note that due to the presence of opaque aspiration across a prefix boundary in Granada-type dialects it would be tempting to analyse such words with the use of Output-Output correspondence (e.g. Transderivational Correspondence proposed by Benua 1997), whereby the output form of the prefix must be uniform 
across all the stems to which it attaches. However, the viability of such a solution is only apparent: a prefix is not an independent word and therefore cannot serve as the base for an $\mathrm{O}-\mathrm{O}$ relation. ${ }^{29}$ This problem has been addressed by several authors whose analyses are briefly discussed below.

\subsection{Kenstowicz (1996)}

One output-based solution might be to propose a specific constraint that would apply to problematic cases. In his 1996 article, Kenstowicz introduces UNIFORM EXPONENCE, whose mandate is to "minimize the differences in the realization of a lexical item (morpheme, stem, affix, word)" (Kenstowicz 1996: 21). Thus, aspiration across a prefix boundary should be viewed as an instance of allomorphy minimisation: both deshecho and descalzar can be accounted for. As long as the UNIFORM EXPONENCE constraint is ranked above IDENT, the morpheme deswill always be realised in the same way. Nevertheless, Kenstowicz's analysis collapses when he takes inflected forms into account (e.g. the plural meses 'months' realised as [me.seh] as opposed to the singular mes 'month' realised as [meh]). In such cases, the desired result is non-uniformity: Spanish presents a crucial discrepancy between the singular and the plural forms and no output correspondence obtains. Faced with these facts, Kenstowicz himself concludes that UNIFORM EXPONENCE must be restricted to the prefix des-, which definitely is a suboptimal solution in OT: morphemic liberty in this respect might lead to postulating an unlimited number of morpheme-specific constraints.

\subsection{Colina $(1997,2002)$}

Colina (1997) makes an attempt at solving the same issue, providing a slightly modified analysis of the Granada data with the use of virtually the same set of constraints as Kenstowicz. She mentions UNIFORM EXPONENCE and another faithfulness constraint originally introduced by him: BASE IDENTITY. The second constraint requires that the components of complex output structures preserve their "original" forms. For instance, the word mes 'month' in mes entero 'the whole month' must have the same output structure as when produced in isolation, in this case: [meh]. According to Kenstowicz, such paradigmatic relations are necessary as they ensure maximal uniformity of inflected forms and

\footnotetext{
${ }^{29}$ This is duly noted e.g by Baković (1999) who provides a TCT analysis of aspiration in Spanish.
} 
morphologically complex words whose bases are independent words. ${ }^{30}$ Nevertheless, against this background, base identity cannot be ensured for the word mes at all times. For the plural form meses 'months', an unaspirated output form of the root is generated ([me.seh]), which results in a discrepancy between the different instantiations of the stem mes (mes, meses, mes entero). BASE IDENTITY must be mute. ${ }^{31}$

The difference between the two constraints used by Kenstowicz (1996), and later Colina (1997), is that BASE IDENTITY compares outputs to independently occurring words (that form part of these outputs), while UNIFORM EXPONENCE compares pairs of bound and unbound allomorphs. In her analysis of Granada Spanish, Colina uses BASE IDENTITY when referring to inflected forms such as plural meses, and analyses prefixed words and phrases in terms of UNIFORM EXPONENCE. She explains that mes $+e s$ is subject to BASE IDENTITY because $m e s$ is an independent word. At the same time, UNIFORM EXPONENCE is mute in the evaluation of the word meses, as "we are not comparing one morpheme with its allomorphs as in [the prefix] des-; we are comparing competing analyses of the plural meses with its independently occurring constituent - the singular [meh]" (Colina 1997: 20). However, the rejection of UNIFORM EXPONENCE in plural forms lacks sufficient motivation. Apart from functioning as an independent word, mes is also a morpheme, the same that is encountered in the plural meses. Thus, unavoidably, we are analysing two allomorphs of the same morpheme (realized as [meh] in singular and as [mes] in plural). Whether this information is accessed or made use of by a given constraint is another issue. In this case, however, it follows from Kenstowicz's definition of UNIFORM EXPONENCE that meses must be evaluated by this constraint (he refers to morphemes,

\footnotetext{
${ }^{30}$ The exact definition of the constraint is as follows: "Given an input structure [X Y] output candidates are evaluated for how well they match $[\mathrm{X}]$ and $[\mathrm{Y}]$ if the latter occur as independent words" (Kenstowicz 1996: 8), which can be interpreted in two different ways: either both X and Y must be independent words (which excludes comparisons to affixes) or one of the components, X or Y, must be an independent word (which allows for the use of BI with respect to affixed words as compared to their bases). At the same time, Kenstowicz analyses derived and inflected forms in various languages with the use of this constraint, which tips the scales in favour of the second interpretation. He also mentions cyclicity effects: "One of the properties that distinguishes the Base Identity constraint from the cycle is that identity effects will come into play only to the extent that the immediate constituents composing the complex structure constitute independently occurring outputs over which the identity constraint can be computed" (Kenstowicz 1996: 9).

${ }^{31}$ This can be solved in the following way: Base Identity is ranked low. The stem mes is produced without aspiration due to transparent syllabification in meses, and with aspiration elsewhere (in phrase-level phonology). No paradigmatic relations ensue. The behaviour of prefixes, however, is a challenge, as mentioned above.
} 
stems, affixes and words). Second, it would be difficult to motivate the use of UNIFORM EXPONENCE with respect to bound morphemes (prefix des-) on the one hand, and isolated words in sequences such as mes entero 'the whole month' on the other, and exclude the plural meses at the same time. Furthermore, as Colina herself points out, a problem arises in dialects which aspirate $s$ but not across a prefix boundary before a vowel, in which case the question is how to rank UNIFORM EXPONENCE to generate the correct result. Colina suggests that in such dialects the constraint should not apply to prefixes. This, in turn, would imply a language-specific restriction on a universal constraint. Thus, although Colina (1997) presents an interesting alternative to other OT accounts of Spanish aspiration, her analysis may result problematic in more complex cases such as the Granada dialect or varieties such as Chilean, in which deletion further obscures output-output relations. ${ }^{32}$

Colina (2002) improves on both Kenstowicz (1996) and Colina (1997) in taking a prosodic perspective on output-output evaluation. She proposes a recursive PW structure for prefixed words and a corresponding output-output constraint mandating identity between prosodic words. This constraint applies both to PWs and to prefixes adjoined to PWs as a part of such recursive structures. As argued by Wiltshire (2006), this involves a rather complex procedure whereby both preconsonantal and prevocalic instantiations of the prefix have to be compared at once to determine whether the aspirated or non-aspirated variants are more optimal. As a result, the output structure of the prefix in prevocalic contexts is chosen based on a word in which the prefix is syllabified differently, i.e. the output [deh] in de.[h]hecho is selected based on analogy to [deh] in $d e[\mathrm{~h}]$.calzar. Although this is a possible line of reasoning in output-output phonology, it may be difficult to maintain vis à vis the Chilean data in which deletion is a legitimate process, but not in prefixed forms, and prefixed forms behave differently than sequences of free-standing words. In such a case, the PW structure might have to be changed to accommodate the data. ${ }^{33}$ The same ap-

\footnotetext{
${ }^{32}$ I cannot provide a full discussion of Colina's account for reasons of space. An exhaustive analysis is presented in Broś (2015).

${ }^{33}$ Along similar lines, Colina (2009) attributes dialectal differences to different prosodic representations. In her account, prefixed words are comparable to each other based on correspondence with the allomorph of the prefix that is encountered in preconsonantal position. The constraint responsible for the choice of an opaquely aspirated form over the non-aspirated form in e.g. deshecho in Granada is IDENTPRWD - an anti-allomorphy constraint ranked below the coda condition. Face (2002) presents a somewhat similar analysis in which a special constraint (Uniform Exponence in Phonological Domains) is used. Here, prefixes are assigned the label of phonological domains, the same as independent words, despite the fact that they bear no stress and deviate from words in other ways.
} 
plies to other Spanish dialects that present aspiration but do not pattern with the Granada variety. By contrast, the analysis presented in this paper involves uniformity in terms of prosodic structure building across dialects. Whether a rearrangement in this respect is legitimised by other processes or theoretically superior to the option presented here requires further study.

\subsection{Summary of Output-Output accounts}

In the light of the above, it may be concluded that base identity or surface form uniformity, however defined, does not constitute a valid solution for the Spanish cases discussed so far. Apparently, only prefixes, and possibly only the prefix des-, present the kind of uniformity argued for by Kenstowicz (1996) and Colina (1997). There is no need to resort to morphology by means of an affixspecific constraint. The assignment of a prosodic word or similar status to prefixes along the lines of Colina $(2002,2009)$ or Face (2002) is an improvement which makes it possible to account for dialectal variation in a more uniform fashion. Nevertheless, in view of the data presented in this paper, and the additional complication added by $s$ elision, I argue that a solution proposing uniform prosodic representations across dialects and indirect morphological influence resulting from framework architecture (strata) is an insightful alternative to previous accounts. The ultimate solution to the problem presented by the deletion cum aspiration plus prefixes cases discussed here cannot be warranted by recourse to output-output correspondence only. By contrast, the analysis produced under Stratal OT is successful in that it requires crucially two stages of derivation - each with a separate ranking. Thus, prefixes are added at the word level and (in the Chilean case) deletion takes place at the phrase level, where syntax comes into place. Resyllabification is either there all along or activated at the phrase level, depending on the dialect (the latter case being true for the Granada variety). Naturally, dialects with no aspiration/deletion interplay constitute an even more straightforward case and do not challenge the analysis presented in this paper. What is more, the differences in the behaviour of prefixes and suffixes in Spanish are captured by the simple assumption that suffixation is a stembased process that does not involve a recursive prosodic word structure. ${ }^{34}$

A reviewer notes that a threefold approach might save the analysis of at least some of the presented data. Indeed, Granada Spanish can be addressed

\footnotetext{
${ }^{34}$ Although the level at which suffixation takes place is a separate issue which goes outside the scope of this paper and shall not be further pursued here.
} 
properly if a distinction is made between derivational and inflectional outputoutput relations along the lines of McCarthy (2005a). Given the fact that derivational relations are asymmetrical, as suggested by Benua (1997), the TCT model is the correct path to follow in affixed words and in phrase phonology as they both present cyclic effects and allow for clear base identification. For Spanish phrases such as unas enfermedades 'some diseases' or una vez entré 'once I entered' with overapplication of aspiration across a word boundary the base would be identified from the forms produced in isolation, with markedness governing aspiration at the cost of unfaithfulness to the input (unas [u.nah], vez [beh]). BASE IDENTITY could be used to determine the direction of the paradigmatic pressure: from the base in isolation to the word in a sequence. O-O faithfulness outranks I-O faithfulness. The second part of the analysis consists in reflecting the behaviour of inflected forms for which a base cannot be identified. Such paradigmatic relations are crucially symmetrical (McCarthy 2005a), which means that all the forms within a paradigm can influence each other. In this case, $\left.{ }^{*} \mathrm{~s}\right] \mathrm{CODA}$ induces the change $\mathrm{s}=>\mathrm{h}$ in the coda $(v e[\mathrm{~h}])$, and the ranking $\operatorname{IDENT}(\mathrm{Pl})>>$ OP-IDENT $(\mathrm{Pl})$ prevents it from overapplying in onset position in inflected forms (be[s]es). The OP-IDENT(Pl) constraint is an analytical tool used as a part of the Optimal Paradigms model and is used exclusively to govern inflectional relations. The resultant ranking for both prevocalic and preconsonantal forms in Granada Spanish is *s]CODA $>$ OO-IDENT(Pl) $>\operatorname{IDENT}(\mathrm{Pl})>>$ OP-IDENT(Pl). As for the prefix, this approach requires yet another outputoutput relation: Kenstowicz's UNIFORM EXPONENCE (or the related proposal put forward by Burzio (2005), METRICAL CONSISTENCY). Since the prefix cannot constitute a base, it has to be treated as an affix requiring prosodic and segmental uniformity across contexts. Thus, resemblance beyond the priority of the base problem has to be mandated by a separate constraint. This treatment of paradigmatic relations goes beyond any of the three output-output approaches presented herein (TCT, O-O with UE and BASE IDENTITY, and Optimal Paradigms). Rather, it is a combination thereof. It must be emphasized that such a model is able to account for the Granada data. Nevertheless, the Chilean portion of Spanish eludes this solution. First, its prefixes depart from the behaviour of word sequences, which can be potentially solved by a different ranking of the UE constraint. Second, Chilean admits deletion, which complicates the analysis of phrases. Assuming that deleted forms serve as bases in inflectional paradigms, a ranking paradox may ensue. Across words, the base cannot be reliably chosen. The only solution would be to allow for phrase-level paradigmatic relations at the phrase level only, which is equivalent to introducing strata. Other- 
wise, a sonority- or syllable contact-based model might be adopted in the form of constraints activated to protect word-final prevocalic $s$.

\subsection{Prosodic analyses}

Outside of the output-output realm, Wiltshire $(2002,2006)$ presents a prosodic analysis of aspiration, taking into account the behaviour of prefixes across the different Spanish varieties. She argues that prefix-final behaviour can be attributed to prosodic structure of the type presented in this paper (recursive $\mathrm{Pw}$ ) and to the sensitivity of the $s$ to prosodic boundaries. The crucial constraint responsible for $s$ weakening is therefore Weak $\mid \mathrm{Pw}$ which mandates weakening before word boundaries. Naturally, in words such as (des(calzar)), the $s$ stands before a Pw boundary and hence weakens to [h]. To account for word-internal aspiration in monomorphemes and suffixed words, Wiltshire (2006) proposes Weak $\mid \sigma$. The proposed solution neatly solves a number of problems in dialects presenting both opaque and transparent aspiration. One case, the Río Negro Argentinian Spanish, is similar to Chilean both in word-to-word and prefix behaviour, with the exception that it does not present deletion. Although Wiltshire notes that the constraint *h, when ranked above MAX(Seg), can account for deletion in those dialects that require it (Wiltshire 2002: fn5), she does not further explore the issue with the discrepancies in prefixes in mind. It appears, however, that when deletion is to be prevented in prefixed forms, this ranking is not particularly helpful and incorrect outputs are generated. ${ }^{35}$

Torres-Tamarit $(2012,2014)$ presents an interesting alternative couched in the Harmonic Serialism framework (McCarthy 2008b, 2010). His analysis is based on morphology-prosody mismatches which obviate opaque interactions. Parse and alignment constraints govern stepwise prosodic structure building. They are also in interaction with the coda condition banning $s$ at the right syllable margin and the constraint mandating place identity between the input and the output. In the course of the derivation, the relative ranking of alignment and parse constraints is responsible for the different orders of prosodic structure assignment and allows for prevocalic $s$ debuccalisation in either transparent or

\footnotetext{
${ }^{35}$ Not surprisingly, when candidates with deletion in prefixed forms as well as word sequences are added to tableau (13) presented in Wiltshire (2002:382), outputs with deletion will surface as optimal in all cases, including word-final $s$ before a vowel. This is due to the fact that the analysis presented by Wiltshire is non-derivational and, as argued in the previous sections, without a stratal approach it is impossible to generate the corret forms for Chilean.
} 
opaque contexts. Torres-Tamarit illustrates this with examples of prefixed words and word sequences from different dialects. In the course of a harmonic serialist analysis, he is able to account for overapplication across a word and a prefix boundary. Thus, a compelling analysis is provided as an alternative to Stratal OT that requires no constraint reranking. Granada-type dialects do not pose a problem for this solution. Crucially, however, it does not include cases with deletion as a second weakening strategy. There is no way of generating the correct forms for Chilean. This is due to the fact that, as argued in the previous sections, MAX(Seg) must be ranked below IDENT(PL) to enable deletion instead of aspiration before a consonant or a pause. As we are dealing with phrase phonology here, the three words taken from the sequence una vez entré must be parsed into prosodic words separately and only then prosodified further into a phonological phrase to enable resyllabification. Yet with the low ranking of MAX(Seg) aspiration will always be suboptimal compared to segment deletion. Thus, aspiration cannot be generated. Conversely, if the words una vez entré are parsed together at an earlier step, then resyllabification is enabled and it will always be a better option to resyllabify the $s$ than aspirate it at that point because it will allow for satisfying high-ranked ONSET without an additional violation of IDENT. Once the $s$ is resyllabified, there is no motivation for it to aspirate at a later step (the ranking will not allow it). Thus, despite recourse to stepwise prosodic parsing which helps resolve opacity issues in various Spanish dialects, the modified version of Harmonic Serialism is unable to account for Chilean without constraint reranking. It remains to be seen whether another solution is found within the proposed mechanism.

\section{Summary and conclusions}

The focus of this paper was on two non-conservative Spanish dialects which exhibit different stages of $s$ weakening and different implications for phonology in general, and prosodic structure in particular. The analysis of the data presented in examples (1-4) was provided in accordance with the constraint schemes presented below.

In (25), a Hasse diagram is presented that shows aspiration as a default strategy $(\operatorname{MAX}(\mathrm{Seg})>>\operatorname{IDENT}(\mathrm{PL}))$, as well as misalignment of morphological and prosodic edges (ONSET $>>$ ALIGN-L), i.e. resyllabification across a word and a prefix boundary. This is the case at the word level in Chilean and at the phrase level in Granada Spanish. 
(25) Word level constraint interactions in Chilean $=$ phrase level in Granada Spanish

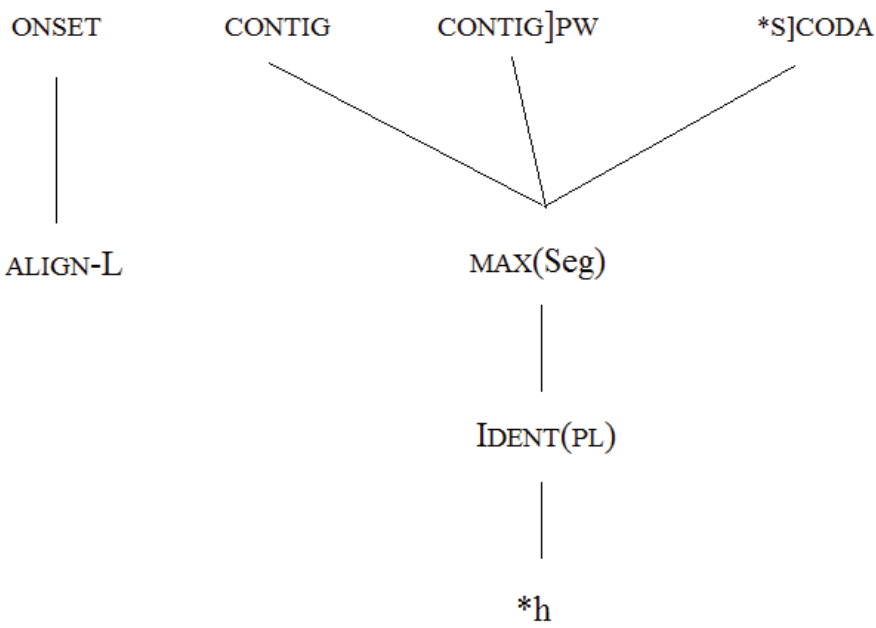

(26) Word level constraint interactions in Granada Spanish

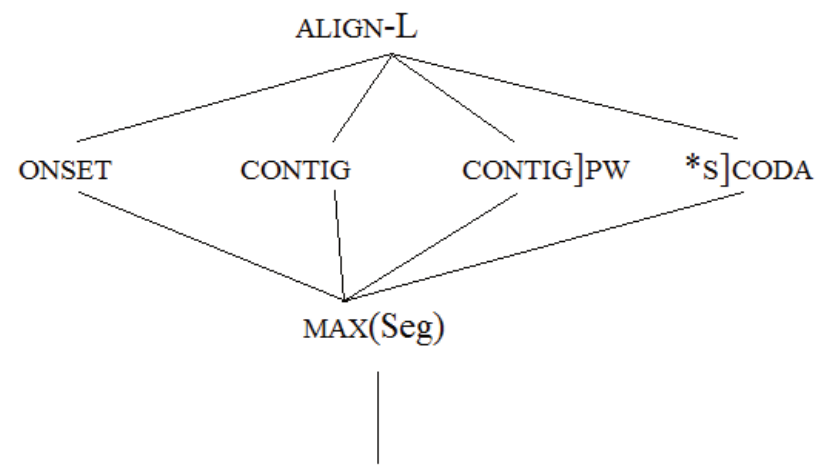

IDENT(PL)

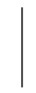

$*_{\mathrm{h}}$ 
(27) Phrase level constraint interactions in Chilean

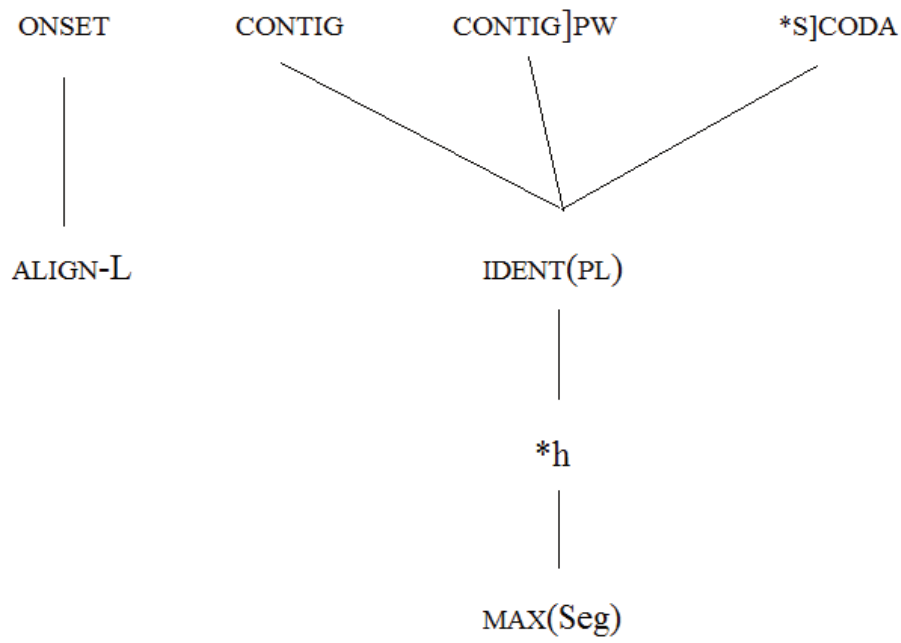

As demonstrated in (26), in Granada Spanish, the crucial ranking lies in ALIGN$\mathrm{L}>>$ ONSET at the word level. Aspiration is a default strategy (it applies both across a word and a prefix boundary, and inside morphemes). Deletion does not ensue. In Chilean, on the other hand, misalignment is valid at the phrase level (27), just as it was at the word level (25). The difference between the levels lies in the ranking of $\operatorname{MAX}(\mathrm{Seg})$, which is demoted to the lowest position at the phrase level in Chilean (27).

To conclude, the analysis of the data provided in this paper points to the fact that not all opacity effects can be solved by standard OT. Both the Granada dialect and Chilean demonstrate how advanced and multifaceted a seemingly unambiguous phenomenon such as $s$-weakening can be. Debuccalisation, in itself an interesting process spreading from word-internal to word-final coda position and beyond, is one of the instantiations of this phenomenon. Complete segmental loss is another. The two cannot be analysed in disjunction from resyllabification, which has the power to either block or obscure weakening. What is more, prefixed forms can behave either like instances of phrase phonology or as monomorphemic words, depending on the variety. At this point, the conclusion to be drawn from the above analysis is that a strictly parallel account of the data cannot be provided, whereas the introduction of derivational levels puts the otherwise disparate facts concerning the distribution of $[\mathrm{s}],[\mathrm{h}]$ and $[\varnothing]$ into order. 
The differentiation between the word and the phrase levels is natural and wellgrounded. It also serves as a vehicle for ousting opacity from the analysed data. At the same time, prefixes should not be neglected in the analysis of these phenomena: they definitely add to the complexity of the Spanish phonology, providing evidence for an extension (or reinterpretation) of the notion of contiguity. This is perfectly grasped within a Stratal OT analysis. ${ }^{36}$

\section{REFERENCES}

Baertsch, K. 2002. An optimality theoretic approach to syllable structure: The split margin hierarchy. ( $\mathrm{PhD}$ dissertation, In:diana University.)

Baković, E. 1999. "Spanish codas and overapplication". In: Schwegler, A., B. Tranel and M. Uribe-Etxebarria (eds.), Romance linguistics. Theoretical perspectives: Selected papers from the 27th Linguistic Symposium on Romance Languages (LSRL). Amsterdam and Philadelphia: John Benjamins. 13-23.

Beckman, J. 1999. Positional faithfulness: An optimality theoretic treatment of phonological asymmetries. New York: Taylor and Francis.

Benua, L. 1997. Transderivational identity: Phonological relations between words. (PhD dissertation, University of Massachusetts at Amherst.)

Bermúdez-Otero, R. 2003. "The acquisition of phonological opacity". In: Spenader, J., A. Eriksson and Ö. Dahl (eds.), Variation within Optimality Theory: Proceedings of the Stockholm Workshop on Variation within Optimality Theory. Stockholm: Department of Linguistics, Stockholm University. 25-36.

Bermúdez-Otero, R. 2006. "Phonological change in Optimality Theory". In: Brown, K. (ed.), Encyclopedia of language and linguistics (vol. 9). Oxford: Elsevier. 497-505.

Bermúdez-Otero, R. 2013. "The Spanish lexicon stores stems with theme vowels, not roots with inflectional class features". Probus 25. 3-103.

Blevins, J. 2004. Evolutionary Phonology. The emergence of sounds patterns. Cambridge: Cambridge University Press.

Booij, G. and J. Rubach. 1987. "Postcyclic versus postlexical rules in lexical phonology". Linguistic Inquiry 18. 1-44.

\footnotetext{
${ }^{36}$ One other account deserves a mention at this point. Outside of OT, Kaisse (1999) provides a comprehensive lexical phonology analysis of several types of dialects differing in the treatment of coda $s$. Although her account does not include dialects with deletion, the proposed solution could be translated into a Stratal OT analysis in a similar way that was proposed in this paper. Kaisse argues against extrinsic rule ordering and relies on lexical strata in her account of interdialectal variation. By assigning the relevant processes of aspiration and resyllabification to different strata (lexical, post-lexical), Kaisse successfully deals with all opacity cases presented in her dialectal classification. As in Stratal OT, processes can be assigned to different levels. At the same time, syllabification precedes all segmental rules in Kaisse's account and resyllabification can be enabled or blocked at different levels depending on the variety.
} 
Borland, K. 2004. "La variación y distribución alofónica en el habla culta de Santiago de Chile". Onomázein 10. 103-115.

Bradley, T. 2005. "Sibilant voicing in Highland Ecuadorian Spanish". Lingua (gem.) 2. 29-42.

Broś, K. 2013. "La aspiración y la pérdida de /s/ en el español de Chile como ejemplo de opacidad". Onomázein 28. 56-71.

Broś, K. 2015. Survival of the fittest: Fricative lenition in English and Spanish from the perspective of Optimality Theory. Cambridge: Cambridge Scholars Publishing.

Burzio, L. 2005. "Sources of paradigm uniformity". In: Downing, L.J., T.A. Hall and R. Raffelsiefen (eds.), Paradigms in phonological theory. Oxford: Oxford University Press. 65-106.

Bybee, J. 2000. "The phonology of the lexicon: Evidence from lexical diffusion". In: Barlow, M. and S. Kemmer (eds.), Usage-based models of language. Stanford: CSLI. 65-85.

Bybee, J. 2003. "Mechanisms of change in grammaticization: The role of frequency". In: Joseph, B. and R. Janda (eds.), Handbook of historical linguistics. Oxford: Blackwell Publishers. 602-623.

Casali, R F. 1996. Resolving hiatus. (UCLA dissertation.)

Cepeda, G. 1990. "La variación de/s/ en Valdivia: sexo y edad”. Hispania 73. 232-237.

Clements, G.N. 1990. "The role of the sonority cycle in core syllabification". In: Kingston, J. and M. Beckman (eds.), Papers in laboratory of phonology I. Between the grammar and physics of speech. Cambridge: Cambridge University Press. 283-333.

Colina, S. 1997. "Identity constraints and Spanish resyllabification”. Lingua 103. 1-23.

Colina, S. 2002. "Interdialectal variation in /s/ aspiration: The role of prosodic structure and output-to-output constraints". In: Lee, J.F., K.L. Geeslin and J. Clancy Clements (eds.), Structure, meaning and acquisition in Spanish: Papers from the 4th Hispanic Linguistics Symposium (HLS). Somerville, MA: Cascadilla Press. 230 243.

Colina, S. 2009. Spanish phonology: A syllabic perspective. Georgetown: Georgetown University Press.

Face, T. 2002. "Re-examining Spanish 'resyllabification"”. In: Cresti, D., T. Satterfield and C.M. Tortora (eds.), Current issues in Romance languages. Philadelphia: John Benjamins Publishing Company. 81-94.

Flemming, E. 1995. Auditory representations in phonology. (PhD dissertation, UCLA.)

Gouskova, M. 2004. "Relational hierarchies in Optimality Theory". Phonology 21(2). 201-250.

Gurevich, N. 2004. Lenition and contrast. The functional consequences of certain phonetically conditioned sound changes. New York: Routledge.

Hayes, B., R. Kirchner and D. Steriade (eds.). 2004. Phonetically based phonology. Cambridge: Cambridge University Press.

Harris, J. 1969. Spanish phonology. Cambridge, MA: MIT Press.

Harris, J. 1983. Syllable structure and stress in Spanish. Cambridge, MA: MIT Press.

Harris, J. 1993. "Integrity of prosodic constituents and the domain of syllabification rules in Spanish and Catalan". In: Hale, K. and S.J. Keyser (eds.), The view from Building 20: Essays in linguistics in honor of Sylvain Bromberger. Cambridge, MA: MIT Press. 177-193. 
Harris, J. and E.M. Kaisse. 1999. "Palatal vowels, glides and obstruents in Argentinian Spanish". Phonology 16. 117-190.

Henke, E., E. Kaisse and R. Wright. 2012. "Is the Sonority Sequencing Principle an epiphenomenon?" In: Parker, S. (ed.), The sonority controversy. Berlin, Boston: de Gruyter Mouton.

Henríquez Ureña, P. 1921. "Observaciones sobre el español de América”. Revista de Filología Española 8. 357-390.

Honeybone, P. 2008. "Lenition, weakening and consonantal strength: Tracing concepts through the history of phonology". In: Brandão de Carvalho, J., T. Scheer and P. Ségéral (eds.), Lenition and fortition. Berlin: Mouton de Gruyter. 9-93.

Hualde, J.I. 1989. "Silabeo y estructura morfémica en español”. Hispania 72. 821-831.

Hualde, J.I. 1991. "Aspiration and resyllabification in Chinato Spanish". Probus 3. 5576.

Hualde, J.I. 2011. "Sound change”. In: van Oostendorp, M., C.J. Ewen, E. Hume and K. Rice (eds.), The Blackwell companion to phonology. Malden, MA: WileyBlackwell. 2214-2235.

Hualde, J.I. and P. Prieto. 2014. "Lenition of sibilants in Catalan and Spanish". Phonetica 71. 109-127.

Jespersen, O. 1904. Lehrbuch der Phonetik. Leipzig and Berlin: B.G. Teubner.

Kaisse, E. 1999. "Resyllabification precedes all segmental rules: Evidence from Argentinian Spanish". In: Authier, B.E. Bullock and L.A. Reed (eds.), Formal perspectives on Romance Linguistics: Selected papers from the 28th Linguistic Symposium on Romance Languages (LSRL). Amsterdam and Philadelphia: John Benjamins. 197-210.

Kaisse, E. and A. McMahon. 2011. "Lexical phonology and the lexical syndrome". In: van Oostendorp, M., C. Ewen, E. Hume and K. Rice (eds.), The Blackwell companion to phonology. Malden, MA: Wiley-Blackwell. 2236-2257.

Kenstowicz, M. 1994. "Syllabification in Chukchee: A Constraints-based analysis". Proceedings of the Formal Linguistics Society of the Midwest. Iowa City: Department of Linguistics, University of Iowa. 160-181.

Kenstowicz, M. 1996. "Base-identity and uniform exponence: alternatives to cyclicity". In: Durand, J. and B. Laks (eds.), Current trends in phonology: Models and methods. European Studies Research Institute and University of Salford. 363-393.

Kiparsky P. 1982a. "From cyclic phonology to lexical phonology". In: van der Hulst, H. and N. Smith (eds.), The structure of phonological representations (I). 131-175.

Kiparsky, P. 1982b. "Lexical phonology and morphology". In: The Linguistic Society of Korea (ed.), Linguistics in the morning calm. Seoul: Hanshin. 3-91.

Kiparsky, P. 1999. "Opacity and cyclicity". The Linguistic Review 17. 351-366.

Kiparsky, P. 2003. "Syllables and moras in Arabic". In: Fery, C. and R. Vijver (eds.), The syllable in Optimality Theory. Cambridge University Press.

Kirchner, R. 1998. An effort-based approach to consonant lenition. (PhD dissertation, UCLA.)

Lamontagne, G. 1997. "Relativized contiguity part I: Contiguity and syllabic prosody". ROA-150.

Lavoie, L. 1996. "Consonant strength: Results of a data base development project". Working Papers of the Cornell Phonetics Laboratory 11. 269-316. 
Lipski, J. 1996. El español de América. Madrid: Cátedra.

Lipski, J. 1999. "The many faces of Spanish /s/-weakening: (Re)aligment and ambisyllabicity”. In: Gutiérrez-Rexach, J. (ed.) Advances in Hispanic linguistics. Papers from the 2nd Hispanic Linguistic Symposium. Somerville: Cascadilla Press.

Lleó, C. 2012. "On the prosodic structure of articles in L1 acquisition of Spanish". In: Larranaga, P. and P. Guijarro-Fuentes (eds.), Pronouns and clitics in early language. Walter de Gruyter. 45-78.

Lloret, M.-R. and J. Jiménez. 2009. “Un análisis ‘óptimo’ de la armonía vocálica del andaluz. Verba”. Anuario Galego de Filoloxía 36. 293-325.

Lloret, M.-R. and C. Pons-Moll. 2016. "Catalan vowel epenthesis as evidence for the free-ride approach to morphophonemic learning". Linguistic Inquiry 47(1). 147157.

Mathews, T. 1994. "Two implosive phenomena and resyllabification in Puerto Rican Spanish". Paper presented at the Annual Meeting of the Rocky Mountain Modern Language Association. Colorado Springs, CO.

McCarthy, J and A. Prince. 1993. Prosodic morphology I: Constraint interaction and satisfaction. Rutgers University Center for Cognitive Science.

McCarthy, J.J. and A. Prince. 1995. Faithfulness and reduplicative identity. (Amherst and New Brunswick: University of Massachusetts and Rutgers University.)

McCarthy, J.J. 2005a. “Optimal paradigms”. In: Downing, L.J., T.A. Hall and R. Raffelsiefen (eds.), Paradigms in phonological theory. Oxford: Oxford University Press. 170-210.

McCarthy, J.J. 2005. "Taking a free ride in morphophonemic learning”. Catalan Journal of Linguistics 4. 19-55.

McCarthy, J.J. 2008a. "The gradual path to cluster simplification”. Phonology 25. 271319.

McCarthy, J.J. 2008b. "Harmony in harmonic serialism”. (Amherst, MA: University of Massachusetts Amherst.) (Available on Rutgers Optimality Archive, ROA-1009.)

McCarthy, J. 2010. “An introduction to harmonic serialism”. Language and Linguistics Compass 4. 1001-1018.

Morris, R. 2000. "Constraint interaction in Spanish/s/-aspiration: three peninsular varieties”. In: Herburger, E., H. Campos, A. Morales-Front and T.J. Walsh (eds.), Hispanic linguistics at the turn of the milennium. Papers from the 3rd Hispanic Linguistic Symposium. Somerville: Cascadilla Press.

Nespor, M. and I. Vogel. 1986. Prosodic phonology. Dordrecht: Foris Publications.

Oroz, R. 1966. La lengua castellana en Chile. Santiago: Facultad de Filosofía y educación, Universidad de Chile.

Peperkamp, S. 1996. “On the prosodic representation of clitics”. In: Kleinhenz, U. (ed.), Interfaces in phonology. Berlin: Akademie Verlag. 102-127.

Peperkamp, S. 1997. “Output-to-Output identity in word level phonology”. In: Coerts, J. and H. de Hoop (eds.), Linguistics in the Netherlands 1997. Amsterdam: John Benjamins Publishing Company. 159-170.

Pérez, H.E. 2007. "Estudio de la variación estilística del fonema/s/ en posición implosiva en el habla de los noticieros de la televisión chilena". RLA, Revista de Lingüistica Teórica y Aplicada 45 (1).I. 101-115. 
Pons-Moll, C. 2011. "It is all downhill from here: A typological study of the role of syllable contact in Romance languages". Probus 23(1). 105-173.

Pons-Moll, C. and M.R. Lloret. 2012/2014. "The free-ride procedure to morphophonemic learning is correct. Some evidence from Catalan vowel epenthesis". Paper presented at 22 MFM. (Also presented at the OCP 2012.)

Prince, A. and P. Smolensky. 1993/2004. Optimality Theory: Constraint interaction in generative grammar. Piscataway, NJ: Rutgers University Center for Cognitive Science.

Robinson, K. 2012. "The dialectology of syllabification: A review of variation in the Ecuadorian Highlands". Romance Philology 66. 115-145.

Roca, I. 2005. "Strata, yes; structure preservation, no: Evidence from Spanish". In: Geerts, T., I. van Ginneken and H. Jacobs (eds.), Romance languages and linguistic theory 2003: Selected papers from Going Romance 2003. Amsterdam and Philadelphia: John Benjamins. 197-218.

Rubach, J. 1997. "Extrasyllabic consonants in Polish: Derivational Optimality Theory". In: Roca, I. (ed.), Derivations and constraints in phonology. Oxford University Press. 551-581.

Rubach, J. 2000. "Glide and glottal stop insertion in Slavic Languages: A DOT analysis". Linguistic Inquiry 31. 271-317.

Rubach, J. 2011. "Syllabic repairs in Macedonian”. Lingua 121. 237-268.

Ségéral, P. and T. Scheer. 2008. "Positional factors in lenition and fortition". In: Brandão de Carvalho, J., T. Scheer and P. Ségéral (eds.), Lenition and fortition. Berlin: Mouton de Gruyter. 131-172.

Selkirk, E. O. 1984. Phonology and syntax. The relation between sound and structure. Cambridge MA: MIT Press.

Selkirk, E. 1995. “The prosodic structure of function words". In: Beckman, J., L. Walsh Dickey and S. Urbanczyk (eds.), Papers in Optimality Theory. Amherst, MA: GLSA Publications. 439-470.

Shepherd, M.A.. 2003. Constraint interactions in Spanish phonotactics: An Optimality Theory analysis of syllable-level phenomena in the Spanish language. (MA thesis, California State University at Northridge.)

Sievers, E. 1876/1893. Grundzüge der Phonetik zur Einführung in das Studium der Lautlehre der indogermanischen Sprachen. Leipzig: Breitkopf and Härtel.

Steriade, D. 2001. The phonology of perceptibility effects: The P-map and its consequences for constraint organization. (Ms., UCLA.)

Strycharczuk, P. and M. Kohlberger. 2016. "Resyllabification reconsidered: On the durational properties of word-final /s/ in Spanish". Laboratory Phonology 7. 1-24.

Tejada Giráldez, M. 2012. "Los factores lingüísticos de la /-s/ implosiva en el nivel de estudios altos de Granada”. Normas. Revista De Estudios Lingüísticos Hispánicos 2. $185-217$.

Torres-Tamarit. F. 2012. Syllabification and opacity in harmonic serialism. (PhD dissertation, Universitat Autónoma de Barcelona.)

Torres-Tamarit, F. 2014. "Phonology-morphology opacity in harmonic serialism: The case of /s/ aspiration in Spanish". In: Côté, M.-H. and E. Mathieu (eds.), Variation within and across Romance languages: Selected papers from the 41st Linguistic 
Symposium on Romance Languages (LSRL). Amsterdam and Philadelphia: John Benjamins. 39-62.

Trubetzkoy, N. 1939. Grundzüge der Phonologie. Göttingen: Vandenhoeck and Ruprecht.

Vennemann, T. 1988. Preference laws for syllable structure and the explanation of sound change. New York: Mouton de Gruyter.

Vida-Castro, M. 2015. "Resilabificación de la aspiración de /-s/ ante oclusiva dental sorda. Parámetros acusticos y variación social”. In: Cabedo Nebot, A. (ed.), Perspectivas actuales en el análisis fónico del habla. Tradición y avances en la fonética experimental. (Normas. Revista De Estudios Lingüísticos Hispánicos, special issue 7). 441-451.

Wiltshire, C. 1999. "Variation in Spanish aspiration and prosodic boundary constraints". 29th Linguistic Symposium on Romance Languages. University of Michigan.

Wiltshire, C. 2002. "Variation in Spanish aspiration and prosodic boundary constraints". In: Satterfield, T., C. Tortora and D. Cresti (eds.), Current issues in Romance languages: Selected papers from the 29th Linguistic Symposium on Romance Languages (LSRL). Amsterdam and Philadelphia: John Benjamins. 375-389.

Wiltshire, C. 2006. "Prefix boundaries in Spanish varieties: A non-derivational OT account”. In: Colina, S. and F. Martínez-Gil (eds.), Optimality-Theoretic studies in Spanish phonology. Amsterdam and Philadelphia: John Benjamins. 358-377.

Zec, D. 1995. "Sonority constraints on syllable structure". Phonology 12. 85-129.

\section{Address correspondence to:}

Karolina Broś

University of Warsaw

Department of Applied Linguistics

Dobra 55

00-311 Warszawa

Poland

k.bros@uw.edu.pl 